\title{
Perceptions of banned drugs in athletics in relation to sport participation, gender, and socioeconomic status
}

Torri P. Hill

West Virginia University

Follow this and additional works at: https://researchrepository.wvu.edu/etd

\section{Recommended Citation}

Hill, Torri P., "Perceptions of banned drugs in athletics in relation to sport participation, gender, and socioeconomic status" (2002). Graduate Theses, Dissertations, and Problem Reports. 1467.

https://researchrepository.wvu.edu/etd/1467

This Thesis is protected by copyright and/or related rights. It has been brought to you by the The Research Repository @ WVU with permission from the rights-holder(s). You are free to use this Thesis in any way that is permitted by the copyright and related rights legislation that applies to your use. For other uses you must obtain permission from the rights-holder(s) directly, unless additional rights are indicated by a Creative Commons license in the record and/ or on the work itself. This Thesis has been accepted for inclusion in WVU Graduate Theses, Dissertations, and Problem Reports collection by an authorized administrator of The Research Repository @ WVU. For more information, please contact researchrepository@mail.wvu.edu. 


\title{
PERCEPTIONS OF BANNED DRUGS IN ATHLETICS IN RELATION TO SPORT \\ PARTICIPATION, GENDER, AND SOCIOECONOMIC STATUS
}

\author{
Torri P. Hill
}
Thesis submitted to the School of Physical Education at West Virginia University in partial fulfillment of the requirements
for the degree of
Master of Science
in
Physical Education

\author{
Andrew C. Ostrow, Ph.D., Chair \\ Edward Etzel, Ed.D. \\ Edward Jacobs, Ph.D. \\ Department of Physical Education \\ Morgantown, West Virginia \\ 2002
}

Keywords: Doping, Perceptions, College Athletes, Drugs, Gender, Socioeconomic Status

Copyright 2002 Torri P. Hill 


\begin{abstract}
Perceptions of Banned Drugs in Athletics in Relation to Sport Participation, Gender, and Socioeconomic Status
\end{abstract}

Torri P. Hill

The purpose of this study was to examine college athletes' perceptions regarding illegal drugs in sport related to sport (team/individual), gender, and socioeconomic status. It was hypothesized that male, team sport, and higher socioeconomic athletes would view drug use in sport as more appropriate. A demographic data sheet and King Drug Doping in Sport Questionnaire (KDSQ) (King, 1991) was administered to 93 athletes in CHAMPS/Life Skills classes at an Eastern Division I institution. To scale reliability and construct validity, Cronbach's alpha coefficients were obtained and a principal components factor analysis with varimax rotation was run. Findings revealed weak Cronbach alpha coefficients, and discrepancies related to factor loading. Two 2x2 MANOVAs (gender/sport and socioeconomic status/sport) were computed. Findings revealed no statistically significant differences in perceptions in relation to sport, gender, and socioeconomic status. The findings are discussed in relation to the existent literature on the perceptions of drug use in sport. 


\section{ACKNOWLEDGEMENTS}

There are several people I would like to thank, because without them this project would have never been completed. I want to thank Dr. Ostrow and my committee for taking the time to aide me in completing my master's thesis and for being understanding for all the changes I have been forced to make along the way. I also want to thank Dr. Althouse for taking the time to help me develop a more sound and accurate measure of socioeconomic status.

Special thanks go to my parents, Ben and Holly Hill for their constant support and belief in me. Also, for always reminding me not to get too stressed out, because it will get done! I would also like to thank my classmates and friends who were there to listen to me complain every step of the way and who helped me out when I had no clue what to do next. Finally, I want to thank to Dr. Sam Zizzi. Without his statistical expertise this paper may have been lacking a results section! 


\section{TABLE OF CONTENTS}

INTRODUCTION 1

METHODOLOGY 6

$\begin{array}{lr}\text { Participants and Sampling } & 6\end{array}$

$\begin{array}{ll}\text { Instrumentation } & 6\end{array}$

$\begin{array}{lr}\text { Procedures } & 8\end{array}$

RESULTS 9

Demographic Data 9

Psychometric Properties of the KDSQ 9

$\begin{array}{ll}\text { Perceptions of Illegal Drug Use in Sport } & 10\end{array}$

DISCUSSION 11

$\begin{array}{ll}\text { REFERENCES } & 15\end{array}$

$\begin{array}{ll}\text { APPENDIX A: Demographic Data Sheet } & 18\end{array}$

APPENDIX B: King Drug Doping in Sport Questionnaire- Part II 19

APPENDIX C: Introductory Letter 25

APPENDIX D: Definition of Drugs $\quad 26$

APPENDIX E: NCAA Banned Drug List 27

APPENDIX F: Review of Literature $\quad 29$

TABLE 1: Descriptive Demographic Data of College Student-Athlete Sample 66

TABLE 2: Demographic Data of Sample Compared to the Institution Population 66

TABLE 3: Principal Components Factor Analysis $\quad 67$

TABLE 4: Cronbach’s Alpha Internal Consistency Coefficients 68

TABLE 5: MANOVA Analyses $\quad 69$ 


\section{PERCEPTIONS OF BANNED DRUGS IN ATHLETICS IN RELATION TO SPORT}

\section{PARTICIPATION, GENDER, AND SOCIOECONOMIC STATUS}

Athletes take many steps to obtain optimal performance, which may include the practice of illegal doping techniques and using banned substances. In a hypothetical situation, elite-athletes were asked if they would be willing to take a special drug guaranteeing them a Gold Medal at the Olympic games, but would kill them in a year. Of the athletes surveyed, over 50 percent said yes (Mirken \& Hoffman, 1978). Athletes have the desire to succeed, be competitive, and win. These are key elements in the road leading to the use of performance enhancement drugs (PED). Athletes feel they must accomplish what seems impossible, and sometimes are desperate to be successful. Thus, the athlete turns to performance enhancement drugs, those legal and illegal, or other methods to give that edge needed to win (Voy, 1991). Performance enhancement drugs are those taken by athletes in order to improve performance and gain a competitive advantage (Anshel, 1998). In addition, athletes are under tremendous pressure from their peers, family, fans, and coaches. Therefore, they search for the competitive edge, which often times leads to unlawful doping (Australian Sport Drug Administration (ASDA), 1999).

Many times athletes are not completely aware of what they are putting in their body. For example, Ben Johnson, a Canadian sprinter, was stripped of his gold medals at the 1988 Seoul Olympics for the use of anabolic steroids. However, Johnson claimed he was not sure exactly what he was taking; only that he was following the instruction of his coach (Voy, 1991). This happens to many athletes, and they often receive a negative stigma from fans and fellow athletes alike. Athletes perceive performers that use anabolic steroids as less honest and less rule oriented (Paccagnelli \& Grove, 1997). Everyone wants an athlete to win due to natural talent, but if the playing field is unfair, the naturally talented athlete will never win. 
In recent years a lot more attention has been placed on doping in sport, which is the use of a substance by an athlete that is foreign to the body or any physiological substance taken in abnormal amounts with the intention of increasing performance in an unfair manner (Green \& Puffer, 1997). In communicating with elite athletes, Williams (1989) stated that many have revealed that right before competition they are in such a mind set that they will take anything to improve performance.

Furthermore, many athletes may not want to use drugs, but feel they must in order to stay even with others. There are two key components that lead to the use of performance enhancement drugs and illegitimate doping. The first is an incredible desire to win, and the second is the perception of the impossibility of reaching this goal by natural means (Voy, 1991). Thus, the athlete may do whatever it takes to accomplish this goal.

There are physical and psychological reasons why athletes choose to use performance enhancement drugs. Athletes turn to doping to perform beyond a normal pain threshold, reduce fatigue, gain intensity, increase awareness, competitiveness, and aggression, and become bigger, faster, and stronger (Ivy, 1983; Verroken, 1996). The result is world records and worldwide fame. Another, and probably more influential reason athletes turn to illegal doping practices is psychological pressure. Pressure comes in all forms, from family, peers, media, coaches, and fans (ASDA, 1999). The pressure placed on athletes to win and set personal bests has resulted in increased drug use among college athletes.

Research shows athletes were most likely to be influenced by a coach who supported the use of performance enhancement drugs, and an authority may coerce an athlete into taking drugs (Diacin, 1999; Verroken, 1996). According to Verroken (1996), doping may be the last resort for the improvement of performance. Williams (1989) disagreed and said that the most effective "drug" an athlete can use to improve performance is effective training. 
Athletes also thought steroid use was associated with having a dedicated attitude, enhanced psychological functioning, and confidence (Anshel, 1991; Fuller \& LaFountain, 1987). Many athletes feel that the pressure to win at all costs, the motivation to succeed, and the need for social recognition supports the use of banned doping practices (King, 1991; Olrich \& Ewing, 1999). Furthermore, Anshel (1991) found that athletes found nothing wrong with taking banned substances to rehabilitate from injury. They also felt drug use may be sanctioned by young athletes through observing their elite models.

Although many athletes may believe drugs are their last resort to better performance, like the general population, most do not condone the use of performance enhancement drugs and were discouraged about the widespread use of prohibited performance enhancement strategies ("Athletes and drugs," 1992; Denham, 1999; Nocelli, Kamer, Francois, Gmel, \& Matri, 1998; Paccagnelli \& Grove, 1997). People, those in and out of the sports arena, want their athletic heroes to be clean, to hold high moral standards and to win by natural talent, not some artificial means (Black \& Pape, 1997; Denham, 1999; Levy \& Ferrone, 1993).

Athletes of different gender and sport perceive the use of PED differently. Several research studies reveal that males have a more positive attitude toward drug use than females (Floyd, Wholeben, Cummings, \& Lawson, 1993; Kindlundh, Isacson, Berglund, \& Nyberg, 1997; Pan \& Baker, 1998; Tricker, 2000). Pan and Baker (1998) found that female athletes associated the use of PED with health risks, enhanced performance, and societal attention. However, male athletes only associated PED use with health risks and improved performance. The way society socializes males and females is different. Thus, behavior that is acceptable for males may be viewed as unacceptable for females. 
The type of sport an athlete participates in may also affect perceptions of PED. A star athlete involved in a team sport may have the whole team counting on him/her to perform well, while an athlete involved in an individual sport only has to worry about performing well for him/herself. When comparing athletes in contact versus non-contact sports it was found that athletes who participated in non-contact sport did not view PED to be highly athletically relevant (Pan \& Baker, 1998). Thus, the researchers concluded that the structure of a sport might articulate an athlete's perceptions toward illegal doping in sport.

Although Pan and Baker (1998) found sport and gender differences in perceptions of banned substances, their research needs to be extended to include socioeconomic status. Individuals of different socioeconomic status are raised differently. Research shows that recreational drug use is more accepted by those of a higher socioeconomic status (Braxton, 1973; Graham, 1996; Lucas and Gilham, 1995; Parker \& Weaver, 1995; Roberts, Fournet, \& Penland, 1995; Webster, 1973). As a result, in some parts of society doping in sport may be viewed as more or less acceptable. Therefore, perceptions of PED may also be different among athletes of different socioeconomic status.

Very few studies have been conducted looking at the perceptions of college athletes regarding illegal doping practices in sport. Also, while it is known that most athletes do not agree with the use of banned substances in a competitive atmosphere, and they want fair play, there is little research looking at the different perceptions athletes may have based on their sport and/or background. King (1991) developed a questionnaire to look at the knowledge, behavior, and attitudes of male and female college athletes regarding drug doping in sport, which includes eight drug subscales. This study used only the attitude portion of the questionnaire. The King Drug Doping in Sport Questionnaire (KDSQ) was constructed using the Delphi method of consensus with a panel of 18 experts and 130 college athletes. Reliability of the KDSQ was determined using the test-retest 
method, and was $\geq .70$ for all drug subscales. Content validity was established using a panel of 18 experts in the field. According to King's (1991) research, the next step is to distribute the survey to college athletes to determine their attitudes related to sport coping and sport-performance drugs.

There were two major questions the researcher posed in this study. The first was whether college student athletes have different perceptions of illegal drug use in sport in relation to demographic differences, including gender and socioeconomic status. The second research question was whether college student athletes have different perceptions of illegal drug use in sport based on the sport they participate in, i.e., team versus individual. It was hypothesized that male student athletes would view illegal drug use in sport as more appropriate than female students athletes. In addition, student athletes of a higher socioeconomic status would view illegal drug use in sport as more appropriate than student athletes of a lower socioeconomic status. Lastly, it was hypothesized that male students involved in team sports would view illegal drug use in sport as more appropriate than females or athletes involved in individual sports.

With the answers to these questions it is the hope of the investigator to continue this research by developing a drug education program that addresses the different perceptions college student athletes may have about doping in sport. 


\section{METHODOLGY}

\section{$\underline{\text { Participants and Sampling }}$}

The subjects for this study were 93 college student-athletes $(\underline{n}=65$ males; $\underline{n}=28$ females $)$, with a representative percentage of gender, race $(\underline{n}=76$ Caucasian; $\underline{n}=17$; Non-Caucasian $)$, and team $(\underline{\mathrm{n}}=58)$ and individual $(\underline{\mathrm{n}}=34)$ sport athletes according to the demographics of the institution. The sample was a matter of convenience. The location of the subject pool was from student athletes enrolled in CHAMPS/Life Skills courses at an Eastern Division I University. IRB approval was obtained from the participating institution.

$\underline{\text { Instrumentation }}$

The classification variables of gender, socioeconomic status, and type of sport were measured first using a demographic data sheet (see Appendix A). Socioeconomic status was measured by asking questions regarding an athlete's family income, family size, and education and occupation of both parents. The answers to these items were categorized and given a numeric value. Adding the scores to these items and ranking the total gave an overall socioeconomic status score (Hollingshead $\&$ Redlich, 1958). Two socioeconomic categories of low and high were created using a median split based on the scores obtained from the participants. The reliability of establishing a participant's socioeconomic status in relation to the variables mentioned above is $>.85$ (Hollingshead \& Redlich, 1958).

In order to measure student-athletes' perceptions of doping in sport, Part II of the KDSQ was used (see Appendix B). This part of the questionnaire looked at the attitudes student-athletes have regarding the use of illegal drug use in sport. Perceptions of five sport coping and three sportperformance drugs were measured on a five-point Likert Scale with 1 being Strongly Agree and 5 being Strongly Disagree. The more an athlete agreed with an item the lower the score and thus a more positive perception regarding drug use in sport. The sport-coping drugs included alcohol, smokeless 
tobacco, marijuana, cocaine, and prescription painkillers. The sport-performance drugs included stimulants, human growth hormone, and steroids. The author of the questionnaire established these categories. There were few instruments that look at the perceptions of drug doping in sport. The KDSQ was chosen because it was developed for college student-athletes and has some evidence of reliability and validity.

The KDSQ was constructed using the Delphi method of consensus with a panel of 18 experts and 130 college athletes. The questionnaire was developed in two parts to assess the knowledge, behavior, and attitudes of male or female college athletes toward sport-coping and sport-performance drugs. A sport-coping drug is a substance to help an athlete cope with the stresses of performing or to calm down after a competition (i.e. alcohol, pain killers, marijuana), while a sport performance drug is a substance to help an athlete improve performance before or during competition (i.e. anabolic steroids, human growth hormone) (King, 1991). The first part of the questionnaire measures behavior and knowledge about sport-coping and sport performance drugs. The second part of the questionnaire, used in this study, measures attitudes toward sport-coping and sport-performance drugs. Reliability of the KDSQ was determined using the test-retest method (King, 1991). The reliability on all drug subscales was $\geq .70$. Content validity was established using the panel of 18 experts in the field. Construct validity was established by asking the panel of experts to indicate whether each item was written to assess knowledge, behavior, or attitude. Construct validity for the eight drug subscales had a decision rule of $\geq .80$ among the panel of experts. The decision rule meant that $80 \%$ of the members on the panel agreed to what each item on the questionnaire was measuring. Content and construct validity were determined by expert judgment, and it was concluded that the questionnaire was an accurate assessment of knowledge, behavior, and attitudes of college athletes about sport-coping and sport-performance drugs. 


\section{$\underline{\text { Procedures }}$}

This study involved the use of a survey instrument to collect information on student-athletes' perceptions of illegal drug use in sport. The classification variables examined were gender, socioeconomic status, and type of sport (individual or team). The dependent variables were the perceptions of illegal drug use in relation to alcohol, smokeless tobacco, stimulants, human growth hormone, marijuana, steroids, cocaine, and prescription painkillers.

After approval was obtained, the researcher contacted the instructor of the CHAMPS/Life Skills classes and set up times to distribute the questionnaire. The administrative time involved for each participant was approximately 15 minutes. Each participant completed the questionnaire in a classroom setting and received a packet of information containing the study materials from the researcher. Each packet contained an introductory letter (see Appendix C), a demographic data sheet, the KDSQ, and a list of drug definitions (see Appendix D). The introductory letter explained the nature and importance of the study, provided instructions for participation, and thanked the athlete for his/her participation. Each participant kept a copy of the introductory letter, which provided all the necessary contact information to ask questions or request additional information about the study.

Because the subject of illegal drug use in sport is a socially sensitive topic, and the instrument was a self-report measure, the student-athletes may not have accurately reported their true attitudes for concern of what the researcher or others would think. The guarantee of confidentiality was the action initiated to minimize this concern. In addition, the researcher did not ask the participants about their personal involvement with illegal drug use in sport. 


\section{RESULTS}

\section{$\underline{\text { Demographic Data }}$}

Descriptive and inferential statistics were used to interpret the results. Descriptive statistics that summarize the demographic data of college student-athletes $(N=93)$ can be found in Table 1. The demographic data of the college student athletes are presented in terms of gender, race, socioeconomic status (high or low), and sport played (team or individual). The average age for the participants was 18.72 years, with a standard deviation of 1.07. The demographic data, other than age, of the sample of college student athletes is somewhat comparable to the demographic data of the entire institution in which they were enrolled and the demographic data of all the athletes at the institution (NCAA, 2000). The demographic data of this sample of college student athletes compared to the entire student body and the entire athletic population is presented in terms of gender, race, and sport played and are summarized in Table 2. In relation to gender, the sample was comprised of slightly less females than the total student athlete population (39\%) and the entire student body (46 $\%)$, respectively. The sample was comprised of more than twice the number of minorities (18.3\%) than the entire student body $(8.1 \%)$, while the entire athletic population had a larger number of minorities $(26.6 \%)$ than the sample.

Psychometric Properties of the KDSQ

A principal component factor analysis with varimax rotation was computed to examine the construct validity of part II of the KDSQ. In addition, Cronbach alpha internal consistency coefficients were computed for each drug subscale.

The principal components factor analysis with varimax rotation run on the KDSQ $(N=93)$ was constrained into two factors, based on the two scales postulated by the author of the KDSQ. The results of the factor analysis are shown in Table 3. Four of the drugs, stimulants, human growth hormone, marijuana, and steroids, had a majority of their items load on their appropriate factor of 
either a sport coping or sport performance drug. However, three of the drugs, alcohol, smokeless tobacco, and cocaine, did not have a majority of their factors load appropriately, while prescription painkiller items appeared to load on the sport performance factor rather than the sport coping factor. The two factors of sport coping and sport performance drugs only accounted for $29.36 \%$ of the variance in participants' responses to Part II of the KDSQ. It should be noted that when the number of factors was not constrained (i.e. eigenvalues greater than 1 were accepted), 17 factors emerged accounting for $73.62 \%$ of the variance.

Cronbach's alpha coefficients for each drug subscale on the KDSQ are reported in Table 4. For two drug subscales the Cronbach's alpha coefficients were $\geq .73$, while three other drug subscales had a coefficient $\geq .59$. Responses to the items for cocaine and human growth hormone did not evidence internal consistency. Smokeless Tobacco only had two items: thus, a Cronbach alpha coefficient was not computed.

\section{$\underline{\text { Perceptions of Illegal Drug use in Sport }}$}

Two two-way MANOVAs were run to see if statistically significant differences in the perceptions of illegal drug use in sport existed as a function of these participants' sport, gender, and socioeconomic status. A 2 (gender - male/female) X 2 (sport type - team/individual) MANOVA was computed to determine if gender, sport type, or the interaction of these two variables affected perceptions of illegal drug use in sport. No statistically significant differences were found for either main effect or the interaction. A 2 (sport type - team/individual) X 2 (socioeconomic status - high/low) MANOVA was computed to determine if sport type, socioeconomic status, or the interaction of these two variables affected perceptions of illegal drug use in sport. No statistically significant differences were found for either main effect or the interaction. The results of these MANOVA analyses are presented in Table5. 


\section{DISCUSSION}

Previous to this current investigation, there has been little research conducted on student athletes' perceptions of illegal drug use in sport. The results indicated that there were no statistically significant differences found between male and female, team and individual, or high and low socioeconomic status student athletes. In addition, there were no statistically significant differences found for the interactions among gender, sport, or socioeconomic status.

While the results of this study did not provide support for the predicted hypotheses, there may be several reasons why statistical significance was not found. First, the category of socioeconomic status had only two groups, high and low. Therefore, the participants at the higher end of the low category and the lower end of the high category were similar in socioeconomic status, and could have comprised a middle category, had their been enough participants. Perhaps the lack of statistical support is also due, in part, to the sample size. Based on a previous study that found statistically significant differences in relation to gender and sport, the sample size was larger $(\underline{\mathfrak{n}}=237)(\operatorname{Pan} \&$ Baker, 1998).

The reason the sample size was small was partly due to the resistance received from several of the institutions approached for their participation in the study. Although the names of the institutions would be kept confidential, they were weary of their athletes answering questions about drugs in sport, even though the athletes would only be asked about their perceptions and not actually usage. The institutions may have perceived the information gathered as providing negative publicity. Thus, other researchers interested in the area of drug use in sport may anticipate difficulties in obtaining adequate sample sizes.

In addition to the small sample size, almost all of the participants were freshman. Therefore, they may not have faced the pressures associated with their sport and many were still trying to find their role within the team. Another aspect unique to this sample is that all of the students were 
enrolled in the CHAMPS/Life Skills class where they had received one lecture on drug use, which may have influenced the way they responded to the questionnaire. Lastly, the psychometric properties of the KDSQ were questionable.

Psychometric data obtained through the calculation of Cronbach's alpha internal consistency coefficients and principal components factor analysis with varimax rotation on the KDSQ may explain why statistically significant differences may not have been found. Only two of the eight drugs, alcohol and prescription painkillers, had Cronbach alpha coefficients $\geq .70$. While two other drugs have coefficients approaching .70, four of the drugs had coefficients $\leq .59$. Thus, the KDSQ lacked internal consistency. Therefore, the participants' responses to their perceptions of illegal drug use in sport may not have been an accurately assessed.

Further evidence for this premise is noted in that the principal components factor analysis with varimax rotation did not provide evidence for the construct validity of the KDSQ. When the items were forced into two factors, sport coping and sport performance drugs, the variance accountable for each factor was $18.09 \%$ and $11.27 \%$, respectively. Thus, over $70 \%$ of the variance in participants' responses to the KDSQ was not accounted for. Only four of the drugs, stimulants, human growth hormone, marijuana, and steroids, loaded according to how author originally conceived the KDSQ. However, at least $50 \%$ of the items for each drug loading on the proper factor. Alcohol, smokeless tobacco, and cocaine had $40 \%$ or less of their items load on the intended factor according the original development of the KDSQ. An interesting result of the factor analysis was that prescription painkillers had a $75 \%$ loading on the opposite factor than was indicated on the original KDSQ. Originally it was said to be a sport-coping drug. However, it loaded on the sport performance factor. This may be because many athletes may take a prescription painkiller in order to perform during practice or competition. Thus, it may be perceived as a sport performance drug, because without it the 
athlete could not participate. It is important to point out that when the factor analysis was not forced into two factors, 17 factors emerged with an eigenvalue $\geq 1.0$. These factors accounted for $73.62 \%$ of the variance on the KDSQ.

There may be several ways for Part II of the KDSQ to be improved. First, the drug items on the instrument should be updated so that the most popular drugs that athletes are using are the ones on the questionnaire. For example, many athletes today are using EPO, ephedrine, nandroline, and beta blockers to improve performance. Also, the questions for each drug should be similar in nature so that comparisons can be made across each drug subscale. If the questions for each drug are not alike, there is no way to compare the perceptions that athletes have. The participants should not be informed that drugs listed on the questionnaire are sport-coping or sport performance without further construct validity support.

While the hypotheses of this study were not supported, nevertheless, this descriptive study provided valuable insight and direction to future research in the examination of college student athletes' perceptions of illegal drug use in sport. The results of the study revealed some interesting finds in relation to the participants as a whole. First, in relation to alcohol, the group agreed that partying after a game was socially acceptable behavior, while they disagreed that drinking after a game helped them come down and release tension. In addition, they strongly disagreed that it was okay to drink alcohol before a game to help relieve nervousness. When asked about human growth hormone $(\mathrm{HGH})$, the participants disagreed that using $\mathrm{HGH}$ did not give an athlete unfair advantage and that it did not improve athletic performance. However, they agreed that an athlete would be cheating if he/she used HGH. Finally, in relation to prescription painkillers, participants agreed that is was okay to take them to get over being sore, if they were needed to keep playing, and to prevent an 
athlete from playing with pain. Yet, the participants also agreed that they did not need prescription painkillers to perform to the best of their abilities.

In terms of the future exploration of college student athletes' perceptions of illegal drug use in sport, a sound instrument needs to be developed in which there is sufficient reliability and validity. Currently, the KDSQ is the only instrument available to measure college student athletes' perceptions of illegal drug use in sport. Had a more valid and reliable instrument been available the results may have been different.

Once an instrument is developed, this study should be replicated to see if differences in perceptions of illegal drug use in sport do exist. Future researchers may consider evaluating a larger sample of student athletes and using student athletes from a variety of institutions. Furthermore, future studies may consider sampling a larger number of minority athletes in order to see if differences in perceptions of illegal drug use in sport exist across race or ethnicity. In addition, it would be interesting to compare Division I institutions to Division II and Division III institutions. Athletes in Division II or III competition, usually do end their athletic career in college, whereas Division I athletes may go on to the professional ranks. Therefore there may not be as much on the line when it comes to performing well.

More research needs to be done in the area of drug use in sport. If coaches, trainers, and other professionals in the sports arena are aware of the perceptions athletes have in relation to drug use in sport, better education programs can be developed to deter drug use, not only in the college setting, but in all areas of sport. 


\section{REFERENCES}

Anshel, M. (1991a). A survey of elite athletes on the perceived causes of using banned drugs in sport. Journal of Sport Behavior, 14(4), 283-307.

Anshel, M. H. (1998). Drug Abuse in Sport: Causes and Cures. In J.M. Williams (Ed.), Applied Sport Psychology (pp. 372-397). Mountain View, CA: Mayfield Publishing Co.

Athletes and drugs: a separate pace. (1992). Psychology Today, 25(4), 52-53.

Australian Sports Drug Agency. (1999). ASDA Drugs in Sport. Sydney, Australia.

Retrieved September 8, 2000, from the World Wide Web:

http://www.ausport.gov.au/asda/drugsin.html.

Black, T. \& Pape, A. (1997). The ban on drugs in sports. Journal of Sport and Social Issue, $\underline{21}(1), 83-92$.

Braxton, E. R. \& Yonker, R. J. (1973). Does being urban, poor, black, or female affect youth's knowledge and/or attitudes relating to drugs? Journal of School Health, 43(3), 185-188.

Denham, B. E. (1999). On drugs in sports in the aftermath of flo-jo's death and big mac's attack. Journal of Sport and Social Issue, 23 (3), 362-367.

Diacin, M. (1999). Perceptions of male intercollegiate athletes on performance enhancement substances in sport. Unpublished master's thesis, Bowling Green University, Bowling Green.

Floyd, J. D., Wholeben, B. M., Cummings, C. C., \& Lawson, J. D. (1993). Attitudes toward steroids in amateur athletics: coaches, students, and officials. Illinois Journal for Health, Physical Education, Recreation, and Dance, 34, 8-14.

Fuller, J. R. \& LaFountain, M. J. (1987). Performance-enhancement drugs in sport: a different form of drug abuse. Adolescence, XXII(88), 969-976. 
Graham, N. (1996). The influence of predictors on adolescent drug use. Youth and Society, $\underline{28}(2), 215-235$.

Green, G. A. \& Puffer, J. C. (1997). Drugs and doping in athletes. In M. B. Mellion, W. M. Walsh, \& G. L. Shelton (Eds.), The team physicians handbook (pp. 212-238). Philadelphia: Hanley \& Belfus.

Ivy, J. L. (1983). Amphetamines. In M.H. Williams (Ed.), Ergogenic aids in sport (pp. 101127). Champaign, IL: Human Kinetics Publishers, Inc.

Kindlundh, A. M. S.; Isacson, D. G. L., Berglund, L., \& Nyberg, F. (1997). Doping among high school students in Uppsala, Sweden: a presentation of the attitudes, distribution, side effects, and extent of use. Scandinavian Journal of Social Medicine, 26(1), 71-74.

King, N. D. (1991). Drugs in sport: the development of an instrument to determine the knowledge, behavior, and attitudes of college athletes about sport-performance drugs and sport-coping drugs. Unpublished doctoral dissertation, University of Kansas, Lawrence, Kansas.

Levy, J. \& Ferrone, C. (1993). A survey of attitudes toward adolescent anabolic steroid use by physical education teachers. CAHPER Journal, 59(4), 31-33.

Lucas, W. L. \& Gilham, S. A. (1995). Profiles of drug use and attitudes among young adolescents. Journal of Child and Adolescent Substance Abuse, 4(3), 41-60.

Mirken, G. \& Hoffman, M. (1978). The sportsmedicine book. Boston: Little, Brown. NCAA Self-Study Report 1999-2000: West Virginia University. (2000). Indianapolis, IN: NCAA.

Nocelli, L., Kamer, M., Francois, Y., Gmel, G., \& Matri, B. (1998). Discordant public perception of doping in elite versus recreational sport in Switzerland. Clinical Journal of Sport Medicine, 8(3), 195-200. 
Olrich, T. W. \& Ewing, M. E. (1999). Life on steroids: bodybuilders describe their perceptions of the anabolic-steroid use period. The Sport Psychologist, 13, 299-312.

Paccagnella, M. \& Grove, J. R. (1997). Drugs, sex, and crime in sport: an australian perspective. Journal of Sport and Social Issue, 21(2), 179-188.

Pan, D. W. \& Baker, J. A. W. (1998). Perceptual mapping of banned substances in athletics. Journal of Sport and Social Issue, 22(2), 170-182.

Parker, K. D. \& Weaver, G. (1995). Predictors of alcohol and drug use: a multi-ethic comparison. Journal of Social Psychology, 135(5), 581-590.

Roberts, T. G., Fournet, G. P., \& Penland, E. (1995). A comparison of the attitudes toward alcohol and drug use and school support by grade level, gender, and ethnicity. Drug Education, 40(2), 112-127.

Tricker, R. (2000). Painkilling drugs in collegiate athletics: knowledge, attitudes and use of student athletes. Journal of Drug Education, 30(3), 313-324.

Verroken, M. (1996). Drugs use and abuse in sport. In D.R. Mottram (Ed.), Drugs in sport (pp. 18-55). London: E \& FN Spon.

Voy, R. (1991). Drugs, sport, and politics. Champaign, IL: Leisure Press.

Webster, W. J. (1973). Trends in reported drug usage among public school children. Journal of Experimental Education, 42(2), 80-86.

Williams, M. H. (1989). Beyond training: how athletes enhance performance legally and illegally. Champaign, IL: Leisure Press. 


\section{Appendix A: Demographic Data Sheet}

\section{Demographic Data Sheet}

This form is designed to gather demographic information from the participants in the study. Please fill in all the blanks for the following questions. If you are unsure how to respond feel free to ask the researcher.

Age

Gender:__ $\mathrm{M} \_\mathrm{F}$

Race: __ Caucasian

African American Native American Asian/Pacific Islander Hispanic/Latin American Other

Type of household Single Parent Multiple Parent

Which category best describes your annual household income from all sources?

under $\$ 10,000$ $\$ 35,000$ to under $\$ 50,000$ $\$ 20,000$ to under $\$ 35,000$ $\$ 10,000$ to under $\$ 20,000$ over $\$ 75,000$

The highest grade or year of school completed (including college/graduate school) for:

Male Head of Household Female Head of Household

What is the male head of household occupational title? Explain what he does

What is the female head of household occupational title? Explain what she does

Sport

Division: I I II

Were you recruited to play this sport? Yes No

Are you on scholarship Partial Full No

Years playing sport (including youth and high school)

Have you ever had a drug education class/lecture? __ Yes __ No If yes indicate when and describe 


\title{
Appendix B: Part II: The King Drug Doping in Sport Questionnaire
}

\author{
The King Drug Doping in Sport Questionnaire (part II)
}

The following questionnaire is designed to gather information regarding your attitudes toward banned drugs in sport. Your attitudes related to eight different drugs separated into sport-coping and sport performance categories are included in this questionnaire. Please indicate to which degree each statement reflects your beliefs about banned drugs in sport. There are no right or wrong answers so please respond accurately and honestly. Your results will remain confidential. If you have any questions while responding please ask the researcher.

\section{SPORT-COPING DRUG}

\section{$\underline{\text { Alcohol }}$}

DIRECTIONS: Thhe following list contains a series of statements about ALCOHOL. Please circle the number beside each statement that best reflects the degree to which you agree or disagree with that statement.

$\begin{array}{ccclc}\text { STRONGLY } & & \text { NEITHER AGREE } & & \text { STRONGLY } \\ \text { AGREE } & \text { AGREE } & \text { NOR DISAGREE } & \text { DISAGREE } & \text { DISAGREE } \\ 1 & 2 & 3 & 4 & 5\end{array}$

1. It is okay to drink alcohol before

a game to help relieve nervousness $\ldots \ldots \ldots \ldots \ldots \ldots \ldots \ldots 1 \quad 2 \quad 3 \quad 4 \quad 5$

2. Drinking alcohol after a game helps

me "come down" and release tension. ................. $1 \quad 2 \quad 3 \quad 4 \quad 5$

3. Partying after a game is a socially

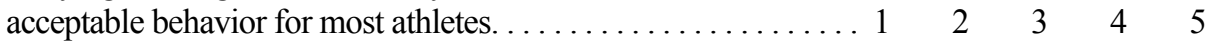

4. Drinking alcohol during the season

will not affect my athletic performance.

$\begin{array}{llll}2 & 3 & 4 & 5\end{array}$

5. Drinking alcohol is an effective way to deal

with the pressures of being an athlete.

$\begin{array}{llll}2 & 3 & 4 & 5\end{array}$

6. Getting drunk helps an athlete

escape from everyday problems.

$\begin{array}{llll}2 & 3 & 4 & 5\end{array}$

7. Drinking alcohol with teammates is necessary

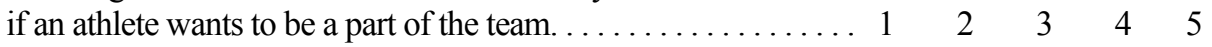

8. Beer is less dangerous to your health

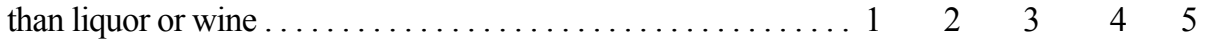

9. Drinking alcohol after a victory

is an acceptable way to celebrate. $\ldots \ldots \ldots \ldots \ldots \ldots \ldots \ldots 1 \quad 2 \quad 3 \quad 4 \quad 5$

10. I have teammates that I believe

are alcoholics 


\section{SPORT-COPING DRUG}

$\underline{\text { Smokeless tobacco }}$

DIRECTIONS: The following list contains a series of statements about SMOKELESS TOBACCO. Please circle the number beside each statement that best reflects the degree to which you agree or disagree with that statement.

$\begin{array}{ccclc}\text { STRONGLY } & & \text { NEITHER AGREE } & & \text { STRONGLY } \\ \text { AGREE } & \text { AGREE } & \text { NOR DISAGREE } & \text { DISAGREE } & \text { DISAGREE } \\ 1 & 2 & 3 & 4 & 5\end{array}$

1. Using smokeless tobacco is a part

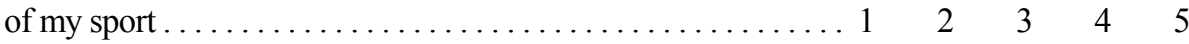

2. I worry about the health of my friends and/or teammate who use smokeless tobacco............. $1 \quad 2 \quad 3 \quad 4 \quad 5$

\section{SPORT-PERFORMANCE DRUG}

$\underline{\text { Stimulants }}$ (i.e. amphetamines, ephedrine, caffeine)

DIRECTIONS: The following list contains a series of statements about STIMULANTS. Please circle the number beside each statement that best reflects the degree to which you agree or disagree with that statement.

$\begin{array}{ccclc}\text { STRONGLY } & & \text { NEITHER AGREE } & & \text { STRONGLY } \\ \text { AGREE } & \text { AGREE } & \text { NOR DISAGREE } & \text { DISAGREE } & \text { DISAGREE } \\ 1 & 2 & 3 & 4 & 5\end{array}$

1. I would consider using stimulants to keep me

from getting fatigued during workouts. ..........

$\begin{array}{lllll}1 & 2 & 3 & 4 & 5\end{array}$

2. If I use stimulants, I would be exposing exposing myself to greater risk of getting injured....

$\begin{array}{lllll}1 & 2 & 3 & 4 & 5\end{array}$

3. Using stimulants can increase an athlete's self-confidence.

$\begin{array}{lllll}1 & 2 & 3 & 4 & 5\end{array}$

4. Because many stimulants can be purchased over-the-counter, they should not be considered illegal drugs. . . . . . . . . . . . . . . . . . . . . . . .

5. It would be necessary for me to use stimulants if my competitors used them ................

6. I would consider using stimulants if I knew I would not get caught.

$\begin{array}{lllll}1 & 2 & 3 & 4 & 5\end{array}$

7. It is okay to use stimulants to keep me awake when I am studying. 
8. I feel that athletes who use stimulants have an unfair advantage. ........

$\begin{array}{lllll}1 & 2 & 3 & 4 & 5\end{array}$

9. I do not need stimulants to

accomplish my goals in sport.

SPORT-PERFORMANCE DRUG

Human Growth Hormone

DIRECTIONS: The following list contains a series of statements about HUMAN GROWTH HORMONE. Please circle the number beside each statement that best reflects the degree to which you agree or disagree with that statement.

$\begin{array}{ccclc}\text { STRONGLY } & & \text { NEITHER AGREE } & & \text { STRONGLY } \\ \text { AGREE } & \text { AGREE } & \text { NOR DISAGREE } & \text { DISAGREE } & \text { DISAGREE } \\ 1 & 2 & 3 & 4 & 5\end{array}$

1. I would use human growth hormones if they would make me a better athlete. $\ldots \ldots \ldots \ldots \ldots \ldots \ldots 1 \quad 2 \quad 3 \quad 4 \quad 5$

2. Using human growth hormone does not give an athlete

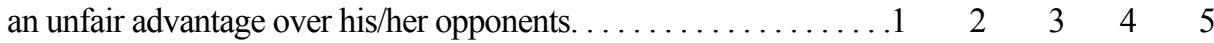

3. I would not take human growth hormone because it is illegal. ... $1 \begin{array}{lllll}1 & 2 & 3 & 4 & 5\end{array}$

4. I would consider taking human growth hormone

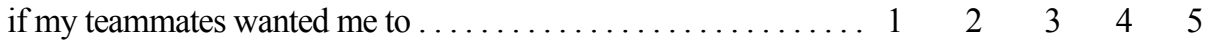

5. I feel that athletes are cheating when they use human growth hormone. $\ldots \ldots \ldots \ldots \ldots \ldots \ldots \ldots 1 \quad 2 \quad 3 \quad 4 \quad 5$

6. I do not believe that human growth hormone improves athletic performance...................... $1230 \begin{array}{llll}3 & 4 & 5\end{array}$

\section{SPORT-COPING DRUG}

Marijuana

DIRECTIONS: The following list contains a series of statements about MARIJUANA. Please circle the number beside each statement that best reflects the degree to which you agree or disagree with that statement.

$\begin{array}{ccclc}\text { STRONGLY } & & \text { NEITHER AGREE } & & \text { STRONGLY } \\ \text { AGREE } & \text { AGREE } & \text { NOR DISAGREE } & \text { DISAGREE } & \text { DISAGREE } \\ 1 & 2 & 3 & 4 & 5\end{array}$

1. Using marijuana does not improve athletic performance. 
2. It is okay for an athlete to use marijuana as a means of relaxing after a game. . . .

3. Marijuana does not harm one's health when used occasionally. $\begin{array}{llll}2 & 3 & 4 & 5\end{array}$

4. It is okay to use marijuana during the off-season. $\begin{array}{llll}2 & 3 & 4 & 5\end{array}$

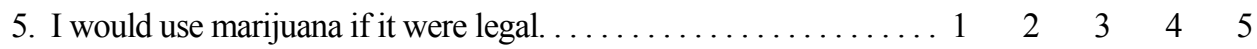

6. I have teammates who use marijuana. $\ldots \ldots \ldots \ldots \ldots \ldots \ldots \ldots 1 \quad 2 \quad 3 \quad 4 \quad 5$

7. I do not need marijuana to cope with the pressures of being an athlete. . . .

\section{SPORT-PERFORMANCE DRUG}

Steroids (i.e. anabolic steroids, androstenedione)

DIRECTIONS: The following list contains a series of statements about STEROIDS. Please circle the number beside each statement that best reflects the degree to which you agree or disagree with that statement.

$\begin{array}{ccclc}\text { STRONGLY } & & \text { NEITHER AGREE } & & \text { STRONGLY } \\ \text { AGREE } & \text { AGREE } & \text { NOR DISAGREE } & \text { DISAGREE } & \text { DISAGREE } \\ 1 & 2 & 3 & 4 & 5\end{array}$

1. I would use steroids if I knew they would guarantee me of achieving my ultimate goals in sport.......... 1 2 $24 \quad 3 \quad 4 \quad 5$

2. An athlete does not suffer adverse effects of steroid

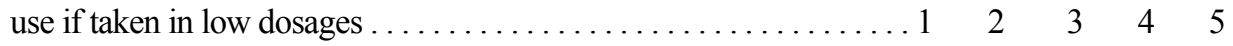

3. I would not be hurting anyone else

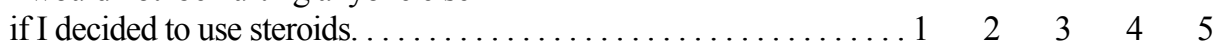

4. Taking steroids is necessary if I am to be competitive in my sport. $\ldots \ldots \ldots \ldots \ldots \ldots \ldots \ldots \ldots 14 \ldots \ldots \ldots$

5. Steroids are only necessary in sports requiring strength.

6. I would consider taking steroids if the coach advised me to.

7. I have not been convinced that steroids are dangerous to my health.

8. I would take steroids if I knew I could better help my team. .

9. I would take steroids for sure if I knew I would not test positive for them. 
10. I feel angry when I see teammates

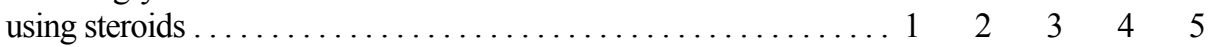

11. I feel that my competitors are cheating when they uses steroids.

12. I do not need steroids to help me become the best athlete I can be.

$\begin{array}{llll}2 & 3 & 4 & 5\end{array}$

\section{SPORT-COPING DRUG}

\section{Cocaine}

DIRECTIONS: The following list contains a series of statements about COCAINE. Please circle the number beside each statement that best reflects the degree to which you agree or disagree with that statement.

$\begin{array}{ccclc}\text { STRONGLY } & & \text { NEITHER AGREE } & & \text { STRONGLY } \\ \text { AGREE } & \text { AGREE } & \text { NOR DISAGREE } & \text { DISAGREE } & \text { DISAGREE } \\ 1 & 2 & 3 & 4 & 5\end{array}$

1. The use of cocaine can enhance my athletic performance.

2. Athletes who test positive for cocaine should be banned from the sport for life. $\ldots \ldots \ldots \ldots \ldots \ldots \ldots \ldots 1 \quad 2 \quad 3 \quad 4 \quad 5$

3. Getting high on cocaine helps an athlete effectively cope with the pressures of being an athlete. $\ldots \ldots \ldots \ldots \ldots \ldots \ldots 1 \quad 2 \quad 3 \quad \begin{array}{llll}4 & 5\end{array}$

4. There is nothing wrong with using cocaine if used only

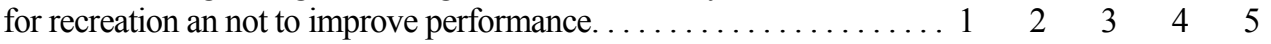

5. Using cocaine can improve an athlete's muscular coordination.

6. There is a problem of cocaine abuse

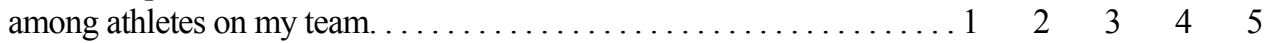

7. I would consider using cocaine if I knew I would not get caught. . .

8. I do not need cocaine to deal with the pressures of being an athlete.

9. I am afraid for people I know who use cocaine.

10. I feel angry when I see teammates using cocaine. 


\section{SPORT-COPING DRUG}

\section{$\underline{\text { Prescription Pain-Killers }}$}

DIRECTIONS: The following list contains a series of statements about PERSCRPTION PAIN-KILLERS. Please circle the number beside each statement that best reflects the degree to which you agree or disagree with that statement.

$\begin{array}{ccclc}\text { STRONGLY } & & \text { NEITHER AGREE } & & \text { STRONGLY } \\ \text { AGREE } & \text { AGREE } & \text { NOR DISAGREE } & \text { DISAGREE } & \text { DISAGREE } \\ 1 & 2 & 3 & 4 & 5\end{array}$

1. It is all right to use Prescription pain-killers to get

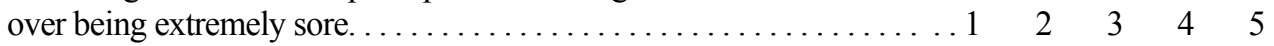

2. Using Prescription pain-killers are necessary in order to be successful in my sport. .........................

3. Prescription pain-killers help me cope with the

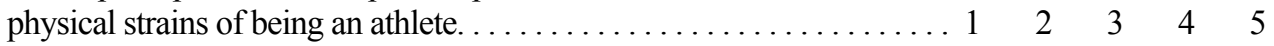

4. Prescription pain-killers are necessary in helping

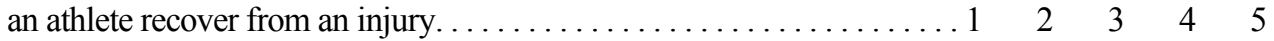

5. Prescription pain-killers are necessary aids

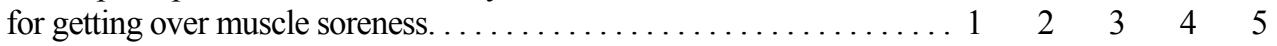

6. If injured, I would take Prescription pain-killers

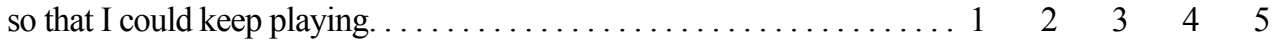

7. There is nothing wrong with using Prescription pain-killers on

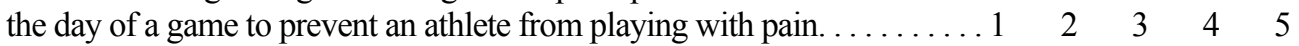

8. I do not need Prescription pain-killers to perform

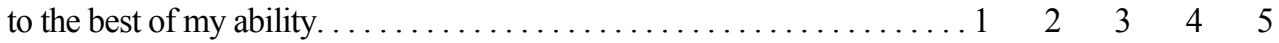


Appendix C: Introductory Letter

November 5, 2001

Dear Athlete,

Hello fellow Mountaineers! My name is Torri Hill and I am a graduate student in the Sport Psychology Program working on my master's thesis under the supervision of my advisor Dr. Andrew Ostrow. I am interested in looking at how college student-athletes perceive banned drugs in sport. I have received permission from the university to contact you for participation in this study.

I am requesting 15 minutes of your time and your voluntary participation in this study. I am interested in finding out what your attitudes are in relation to banned drugs in sport. I am only interesting in your perception, not your involvement with drugs in sport. I believe the findings of this research can benefit student-athletes in the future with regards to tailoring drug education and awareness programs at colleges and universities.

At the beginning of each form there are directions on how to proceed. If you agree to participate and complete all the material, the total amount of participation time is approximately 15 minutes. All of the information you provide will be kept confidential. If you decide to participate, please complete and return the demographic data sheet and the King Drug Doping in Sport Questionnaire to me. It is important to this research that you answer as many questions as possible as honestly as you can. However, you do not have to answer every question if you are not comfortable.

I believe this research is very valuable. Research studies have been done looking at the perception of drug doping in sport. Studies have surveyed professionals in the area of sports, coaches and a variety of athletes. However, studies looking at the perceptions of banned drugs in sport among student-athletes are scarce. Although information is given to incoming athletes regarding drug use and the NCAA implements drug testing of college athletes, no further educational or informational opportunities are provided.

I would greatly appreciate your participation in this study. Thank you.

Sincerely,

Torri Hill

24 Copperfield $\mathrm{Ct}$.

Morgantown, WV 26505

599-6897

torrih@msn.com 
Appendix D: Definition of Drugs

Definitions of Sport Coping and Sport Performance Drugs

Alcohol: ethanol; substance taken orally (drinking), absorbed into the bloodstream that affects the brain and behavior of the individual who consumes it (e.g. beer, wine, liquor) (Kuhn, Swartzwelder, \& Wilson, 1998).

Marijuana: substance from the cannabis plant that is usually smoked, but sometime eaten that relaxes a person and elevates his/her mood followed by drowsiness and sedation (e.g. pot, weed, hash) (Kuhn, Swartzwelder, \& Wilson, 1998).

Smokeless Tobacco (Nicotine): stimulant that increases attention and concentration and has a calming and antianxiety effect (e.g. chewing tobacco, dip, snuff) (Kuhn, Swartzwelder, \& Wilson, 1998).

Steroids: testosterone and drugs that act like testosterone in the body and have the ability to promote muscle growth; may cause feelings of euphoria, great energy, and increased competitiveness (e.g. steroids, roids, juice, andro) (Kuhn, Swartzwelder, \& Wilson, 1998).

Cocaine: a stimulant from the coca plant, usually snorted, that has altering effects and increases endurance; increases heart rate and blood pressure (Kuhn, Swartzwelder, \& Wilson, 1998).

Stimulants: a drug, natural or manufactured by the pharmaceutical industry, that causes increased alertness and a sense of euphoria (e.g. uppers, Ritalin, caffeine, amphetamines) (Kuhn, Swartzwelder, \& Wilson, 1998).

Prescription Painkillers: drugs prescribed by doctors or athletic trainers for the treatment of moderate or severe pain (e.g. vioxx, cortisol) (Kuhn, Swartzwelder, \& Wilson, 1998).

Human Growth Hormone: polypeptide hormone composed of 191 amino acids; injected intramuscularly to stimulate the growth of skeletal and soft-tissue and the mobilization of lipids to increase protein synthesis (Hendrickson \& Burton, 2000). 
Appendix E: NCAA Banned Drug List (NCAA, 2000)

(a) Stimulants:

amiphenazole

amphetamine

bemigride

benzphetamine

bromantan

caffeine

chlorphentermine

cocaine

cropropamide

crothetamide

diethylpropion

dimethylamphetamine

doxapram

ephedrine

ethamivan

fencamfamine

meclofenoxate

methamphetamine

methylphenidate

nikethamide

pemoline

pentetrazol

phendimetrazine

phenmetrazine

phentermine

pictroxine

pipradol

prolintane

strychnine

ethylamphetamine

(b) Anabolic agents

Anabolic steroids:

androstenediol

androstenedione

boldenone

clostebol

dehydrochlormethly-testosterone

dehydroepiandrosterone

dihydrotestosterone

dromostanolone

fluoxymesterone

mesterolone

methandienone

clenbuterol

methyltestosterone

nandrolone

norandrostenediol

norandrostendione

norethandrolone

oxandrolone

oxymesterone

oxymetholone

stanozolol

testosterone

methenolone

(c) Substances banned for specific sports

Rifle:

alcohol

atenolol

metoprolol

pindolo

propranolol

timolol

nadolol 
(d) Diuretics:

acetazolamide

bendroflumethiazide

benzthiazide

bumetanide

chlorothiazide

chlorthalidone

ethacrynic acid

flumethiazide

furosemide

hydroflumethiazide

methyclothiazide

metolazone

polythiazide

quinethazone

spironolactone

triamterene

trichlormethiazide

hydrochlorothiazide

(e) Street drugs:

heroin

THC (tetrahydrocannabinol)

marijuana

(f) Peptide hormones and analogues:

chorionic gonadotrophin

corticotrophin (ACTH)

HCG-human chorionic gonadotrophin) Erythropoietin (EPO)

growth hormone (HGH, somatotrophin)

sermorelin 
Appendix F: Review of Literature

$\underline{\text { Introduction }}$

There is a lot of talk in sport today about the practice of doping and use of drugs. The use of drugs to improve performance has been around since the ancient Olympic games in Greece. However, athletics in the $21^{\text {st }}$ century has become an important social venue, which places pressure on athletes to succeed at all costs. Thus, some athletes resort to the use of substances to improve performance and cope with pressures, claiming they had no other options if they wanted to perform at a higher level. The wide use of drugs in sport has led to a ban on many substances, which some individuals do and do not support. Athletes have also expressed their beliefs regarding the testing and use of doping practices and drugs in sport (Abdenour, Miner, \& Weir, 1987; Albrecht, Anderson, \& McKeag, 1992; Anshel \& Russell, 1997; Diacin, 1999; Floyd et al, 1993; Grenier, 1993; Hamilton \& Stone, 1990; Heldusor \& Bechtol, 1989; Higgins, 1995; Issari \& Coombs, 1998; Olrich \& Ewing, 1999; Pan \& Baker, 1998; Schneider \& Morris, 1993; Tricker, 2000). Although there is widespread use of performance enhancement drugs, most athletes do not condone their use and would like to see clean competition (“Athletes and drugs," 1992). Doping deterrence programs have been in effect for many NCAA (National Collegiate Athletic Association) schools to curb doping in sport. It is important to know the attitudes athletes have regarding doping in sport in order to structure a deterrence program that is effective.

The review of literature is organized into six parts, including the history of doping in sport, doping in modern athletics, use of drugs and doping, perceptions of recreational drug use, perceptions of drug testing, and perceptions of doping in sport. The use of drugs and doping is dividing into recreational drug use and doping in sport. Perceptions of drug testing and perceptions of doping in 
sport are dividing into several demographic categories, such as professionals in the sport's arena, athletes, gender, and sport differences.

\section{History of Doping in Sport}

Since the beginning of formal competition, drugs have been a part of sport. The Greeks incorporated competitive sport into their culture around $800 \mathrm{BC}$. By $400 \mathrm{BC}$ sport achieved the prestige in society similar to what is seen today. The prestige led to corruption and athletes were willing to take anything if it would help them perform better. During the Roman period, gladiators were 'doped-up' to make their fights more aggressive and bloody for the paying spectators, while chariot racers fed their horses a special diet to make them run faster. After these eras, the use of performance enhancing drugs did not emerge again until the late $19^{\text {th }}$ century when Linton, a cyclist, died from a trimethyl overdose. Throughout the early 1900s new performance enhancing techniques became available and the use of performance enhancing drugs became commonplace among athletes (ASDA, 1999).

To combat the unfair competition, the development of anti-doping legislations emerged in the 1960s. The first drugs tests were conducted at the 1968 Mexico Games, and the IOC developed a list of banned substances and illegal doping practices (ASDA, 1999). However, athletes quickly learned how to beat the system through substitute urine samples and stopping usage in enough time to clear the drug from their system. In addition, there is an atmosphere which remains today of the permissiveness of drug usage that is reinforced by the publicity about the lack of enforcement of drug laws (Beresford, 1989). A study conducted by Issari and Coombs (1998) found that some athletes felt an athlete caught using a banned substance should be given two or more chances to test clean. An athlete interviewed for "Athletes and drugs" (1992) said that the world-record holders and medallists get looked over in the drug testing so no disgrace can come to the country. 
In the most recent Olympics, however, some countries tried to avoid such scandals all together and avoid the ridicule the United States has received with regard to anti-doping policies. China left 27 Olympians at home and C. J. Hunter of the United States withdrew from the Olympics claiming it was due to an injury. Later it was revealed that he tested positive four times for nandrolone without being disciplined by American officials. He claims it was a bad diet supplement, but the rest of the world does not trust this explanation "any more than it trusts U.S. anti-doping credibility" (ESPN, 2000). This put the drug-cheating spotlight on the United States. The IOC criticizes the United States for not vigorously testing professional athletes for performance enhancing drugs, and are skeptical because over 200 positive drug tests among Olympic hopefuls in 1999 only led to 10 suspensions. Much of the world press and Olympic movement perceive a country that won the medal chase in Sydney, but does not discipline its world champions (ESPN, 2000).

\section{Doping in Modern Athletics}

Athletes today look for every competitive advantage available, because the rewards of highlevel success are vast and include personal glory. These individuals train harder and longer, and seek every biomechanical and psychological advantage. However, many find this advantage through drugs and feel it is impossible to succeed without them (MacAuley, 1996).

The question many athletes and fans ask today is if everybody involved in high-level competition is engaged in some kind of doping practice. The question remains, because athletes are good at covering up use prior to competition. The sport of cycling has been plagued with this question more than any other sport (Ford, 2000). During the 1998 Tour de France, Jan Ullrich, a top racer, said that doping was all anyone talked about (O’Brien \& Kennedy, 1998). There was a trial in France regarding the widespread doping during the 1998 Tour de France. Richard Virenque, a cycling hero from France said, "These are not racers, they are pedaling test tubes" (Ford, 2000 p. 1). It is believed 
that there is a small group of cyclists at the foreground of doping, and the larger group of cyclists feels it must follow suit to be competitive. Thus, drugs corrupt the world of cycling.

Two myths exist today about the use of drugs in sport. The first is that fans will not pay to see drug-aided athletes, and the second is that athletes using drugs do not have to work hard to succeed (Barnard, 1998). However, both of these myths have been contradicted. Although doping has plagued the cycling arena, fans still come from all over to watch the Tour de France every year. Also, Mark McGwire's record-breaking home run season provided proof that fans will pay to see a drugaided athlete break a record that had been chased for several seasons. In addition, athletes that use drugs work themselves to the limits, because drugs are usually an athlete's last resort to improve performance. Consequently, the Dubin Inquiry has said that a drug-free athlete is usually the losingathlete (Breo, 1990).

Legal versus illegal PED. There are many illegal substances athletes use to improve performance and cope with competition. According to King (1991), drugs used in sports can be classified into sport performance and sport coping drugs. Sport performance drugs are those that can aid an athlete during competition or training. For example, anabolic steroids help a body builder gain muscle mass and become stronger, and erythropoietin helps a runner or cyclist increase the oxygen carrying capacity of the blood (Hendrickson \& Burton, 2000). Through the use of sport performance drugs athletes may become more efficient and in turn improve their performance. In contrast, sport coping drugs are ones that athletes may use to deal with injury or anxiety during or after competition. An athlete may use marijuana to relax and "wind down" from a stressful competition. Athletes may also use a variety of painkillers to help them compete through the pain. 
Classification of Drugs (King, 1991; Hendrickson \& Burton, 2000)

\begin{tabular}{|l|l|}
\hline \multicolumn{1}{|c|}{ Sport Performance Drugs } & \multicolumn{1}{c|}{ Sport Coping Drugs } \\
\hline Anabolic Steroids & Marijuana \\
\hline Human Growth Hormone & Painkillers (over the counter \& prescription) \\
\hline Androstenedione & Alcohol \\
\hline Erythopoietin & Smokeless Tobacco \\
\hline Amphetamines & Local anesthetics \\
\hline Creatine & Cocaine \\
\hline Caffeine & Kava Kava \\
\hline
\end{tabular}

While most of the attention related to doping in sport is given to the illegal substances athletes use, there are many substances competitors use to improve performance that are not deemed inappropriate. According to the NCAA 2000-2001 Manual, certain ergogenic aids are not banned in college athletics (Abell, 2000). Prescription painkillers such as Vioxx and increased doses of ibuprofen are also permitted, along with local anesthetics through local or topical injection. Also included are creatine, St. John's Wort, Kava Kava, and caffeine at appropriate levels (Hendrickson \& Burton, 2000). Although not all doping practices are banned, there is still debate over the unknown long term health risks of using such substances.

The ban on drugs in sport. The information regarding an unfair playing field leads to the question of whether or not the ban on drugs and doping mechanisms should remain. Because the ban is in place, using chemicals to make your body do things it is not capable of is cheating. However, because it is hidden and not easily detectable, it is considered a nasty form of cheating which is tolerated even less (Barnard, 1998). It is argued that if the anti-doping policy were lifted it would result in fairer competition and reduced health risks that are a result of the ban (Black \& Pape, 1997). 
Some feel that unless the ban can promise no athlete is using drugs no contest can be said to be fair. Many believe that after all the advantages of using performance-enhancing techniques are competed away, the most naturally gifted athlete will win. The more widely something is used, the less advantages one can gain from it. In addition, no one can complain that a fellow athlete is using a banned substance while he remains clean, because an athlete has the freedom to choose just like any other athlete (Black \& Pape, 1997).

There are also perceived health risks associated with the ban. It is argued that it is not clear whether banned drugs are harmful to one's health and long-term effects of many substances are unknown. Those in favor of lifting the ban believe it is not necessary to ban the drugs, but to gain the knowledge of safe dosages (Black \& Pape, 1997). In addition, if the anti-doping policy were lifted the health of the athletes could be monitored, resulting in relatively minor medical problems. There would be no need for an athlete to go to the black market to get what he/she needs. With the ban, athletes are denied access to medical advice and a safe dosage of the drug, but if it were lifted, athletes could get reliable information regarding usage and health risks.

A lot of athletes feel the pressure to win at all costs, and the motivation to succeed constitutes the use of banned substances (King, 1991). Furthermore, Anshel (1991a) discovered that athletes found nothing wrong with taking banned substances to rehabilitate from injury. They also felt drug use may be sanctioned by young athletes through observing their elite models. Lastly, many athletes have the perception that they will not get caught (Anshel, 1991a).

\section{$\underline{\text { Use of Drugs and Doping }}$}

Recreational drug use. Studies show that there are several predictors that indicate whether an individual engages in alcohol and drug use. Parker and Weaver (1995) conducted a study to look at the predictors of alcohol and drug us across ethnicity. The data collected was part of the National 
Household Survey on Drug Abuse and included African American, Caucasian, and Hispanic participants. The study examined two dependent variables, alcohol use and drug use, and several types of demographic variables, including socioeconomic status. The demographic variables consisted of age, gender, race/ethnicity, marital status, region, and population size. Socioeconomic status was evaluated based on income, education, and employment status.

Several significant correlation coefficients were found among the dependent variables and explanatory variables. The strongest determinants for alcohol use across all participants were employment status $(\underline{r}=.230)$, education $(\underline{r}=.120)$, and income $(\underline{r}=.098)$. In addition, race $(\underline{r}=-.065)$ and gender $(\underline{r}=-.026)$ were significant in determining alcohol consumption. In looking at the variable of race, sex and marital status were significant determinants of alcohol use for Blacks, but not for Hispanics and Whites. For Hispanics and Whites, population size and region were significant determinations for alcohol consumption. Thus, there was a positive association between alcohol use and socioeconomic status in that individuals working full-time, at a higher income level, with the highest education consumed alcohol more frequently. In addition, Whites and males consumed alcohol more frequently than Hispanics, Blacks, and females.

With regards to determining drug use, employment status $(\underline{r}=.133)$, marital status $(\underline{r}=.115)$, and race $(\underline{r}=-.047)$ were significant across all participants. Age was a significant determinant for Hispanics and Caucasians, but not for African Americans, with older age being a determinant of drug use. Furthermore, population size and region were only significant determinants for drug use among the White participants in that denser, more widely populated areas were a determinant for drug use. According to these findings, individuals who have never been married and are not working are more likely to consume drugs, due to weaker family relations and more reliance on peers for acceptance. 
While the statistics showed a significant relationship across many variables, the results of this study should be looked at with some skepticism due to the large sample size they were obtained with.

Graham (1996) did a study looking at the predictors of adolescent drug use. She wanted to find out what factors contributed to the difference in drug use among gender and race found in previous studies. The factors were age, lunch status, out-of-school suspensions, absenteeism, and grade point average, along with gender and race. This information was accessed through school records, Revised Behavior Problem Checklist teacher ratings, and a 184-item What About You (WAY) student questionnaire. These data sources measure a variety of personal, peer, and family factors for problem behavior. All subscales of these instruments had alpha reliabilities $\geq .66$, with the majority $>.75$. Her sample included a good distribution of people varying in gender, race, and socioeconomic status with $44 \%$ male, $66 \%$ Black, and $50 \%$ on federally funded free lunch, which is how socioeconomic status was measured.

When looking at the variable of race, significantly more White students pay full price for lunch, have significantly higher grade point averages, reported significantly more peer drug modeling, and had significantly higher favorable attitudes toward drug use. However, Blacks were significantly higher on reported negative behavior, attachment to school, social integration, and self-esteem. In addition, Blacks were found to be significantly higher on positive peer influence, commitment to education, belief in rules, self-efficacy, and parental supervision.

Interestingly, when the predictor variables were entered into the equation, the race parameter lost its significance. The results showed that gender, rebellious behavior, and attitudes favoring drug use were the strongest predictors of drug use for Blacks and Whites. Out-of-school suspensions and peer drug modeling were significant predictors for alcohol use among Blacks, while availability, high socioeconomic status, and sex were significant predictors among Whites. Race was a significant 
predictor for only three of the six drugs, including cigarettes, alcohol, and marijuana, with White being the significant predictor in all cases.

While these studies reported that being Caucasian and from a higher socioeconomic status were greater predictors of drug use, Webster (1973) found this to be true only after children entered eighth grade. Prior to eighth grade, Mexican-Americans and those living in lower socioeconomic areas reported higher drug usage. However, the trend shifted again after the students entered grade twelve in that the highest concentration of drug use was in areas of lower socioeconomic status. These shifting trends may have been seen because drug usage between seventh and twelfth grade was highly related to attitudes. Students that reported higher drug usage agreed more with the items related to the acceptability of drug use and drug behavior. The only demographic variable that remained constant for drug usage across the years was gender in that males reported higher drug usage than females.

Similarly, Grenier (1993) found drug usage to be higher among male college students than female college students. In addition, he found white students to use drugs more than non-white students, which agrees with the other research in this area. Furthermore, it was discovered that individuals in fraternities and sororities use drugs more often, which could be an indication that students coming from a higher socioeconomic background have a higher rate of drug use than those from a lower socioeconomic status. Most of the research in the area of recreational drug use is consistent in its findings and reports that males, Caucasians, and those with a higher socioeconomic status have a higher rate of drug use than their counterparts.

Doping in sport. The combination of money in athletics and the desire of everyone to be beautiful has led to a huge market in drugs and supplements (Kuhn, Swartzwelder, \& Wilson, 2000). In today's society, sport has become a significant social institution and being successful is highly 
valued. This has placed pressure on athletes to become the best, which contributes to the increase in drug use (ASDA, 1999). The fact of the matter is that these athletes are putting pressure on themselves. If they did not care so much about what others thought of their performance they would not feel the need to use illegal methods to improve performance. Unfortunately, society has taught these athletes to care how the world views them and to view winning as essential at all costs.

There are many reasons why athletes choose to use performance enhancement drugs. One of the earliest reasons was to help athletes compete through the pain and perform beyond their normal pain threshold (Verroken, 1996). Today athletes use drugs for other reasons. Ivy (1983) claimed many resort to amphetamines to improve performance by reducing fatigue and gaining intensity, while Verroken (1996) says athletes use stimulants to increase awareness, competitiveness, and aggression. Twenty-three percent of athletes surveyed knew of team members that used drugs to get psyched up. All of these team members were male and involved in contact sports (Anshel, 1991a). Many athletes report using a variety of drugs to improve appearances and enhance performance (Kindlundh, Isacson, Berglund, \& Nyberg, 1997; Olrich \& Ewing, 1999; Tangen, Bergsgard, Barland, \& Breivik, 1997). In addition, there are a wide variety of drugs out there to make an athlete bigger, faster, and stronger, which results in world records and worldwide fame.

The pressure placed on athletes to win and set personal bests has resulted in increased drug use among college athletes (Diacin, 1999). Furthermore, if an athlete does not perform well, the athlete must cope with the anxiety, stress, and dissatisfaction received as well as figuring out how to perform better next time. Similarly, if an athlete performs well he/she is expected to do so every time thereafter. Anshel (1991a) reported that of athletes surveyed, $72 \%$ indicated that they took drugs to improve physical performance, while only $21 \%$ said it was to meet psychological needs and $7 \%$ claimed it was to meet social needs. 
Some athletes provide a rationale for their use of performance enhancement drugs. Through in depth interviews, Olrich and Ewing (1999) saw three themes emerge as to the initial use of anabolic steroids. They included curiosity, frustration of seeing others pass them in performance, and reaching a plateau in training. Curiosity is something most humans experience. People want to know what is so great about using artificial methods to improve performance. In addition, most of the athletes that use performance enhancement drugs are at the highest levels of their sport and the difference between winning and losing is a slim margin. When an athlete continues to lose by such a slight difference he/she becomes frustrated and may feel the only way to pass his/her competitor is through doping. Furthermore, athletes at the highest level of their sport often reach a point in training in which no matter what they do they see no improvement. As a result, they may turn to performance enhancement drugs to give them that boost to the next level. A fourth reason for the use of anabolic steroids that emerged, though it was not as strong a determinant, was the environment in which the athletes were involved. The athletes were influenced to start using drugs if the environment was one in which drug use was tolerated.

Tangen and colleagues (1997) conducted a study looking at the differences in the decisionmaking process of doping or not doping among different classes of athletes. They hoped to discover what kind of examination of possibilities and evaluation outcomes are involved in the decision and what kind of cultural, social, and physiological processes influence the decision. The investigators placed each participant in a cultural ethos category based on general ethos types approached from a personality perspective. Depending on a participant's response to a question concerning how he/she generally lives life, the participant was placed in one of four categories (idealist, rationalist, romantic, traditionalist). 
Eleven percent of the sample said they had or are currently using drugs. However, $23 \%$ of the idealists had tried or are currently using drugs. This is twice as many individuals than in the secondhighest group, the rationalists. Thus, individuals who follow their own values and beliefs are more likely to use drugs. In relation to gender, a significant difference was found in that $15 \%$ of men versus $2 \%$ of women reported drug use. The sporting environment also effected drug use, with drug use being more typical in those practicing in a gym. Similarly, the type of activity was also related to drug use. Bodybuilders had the highest rate at $65 \%$, while the rate was only $8 \%$ for those involved in other sports. Furthermore, individuals that were just training on their own reported no prior or current drug use. No significant differences were seen among drug users and non-users in social relations.

Gender and racial differences in drug use are also seen in sport. Kindlundh and colleagues (1997) found that male high school students had more opportunities to try drugs than females. Furthermore, more males than females knew where to obtain drugs. Green, Uryasz, Petr, and Bray (2001) found that females had a significantly lower rate of drug use for steroids, smokeless tobacco, and ephedrine. In addition, Caucasians used amphetamines, ephedrine, and smokeless tobacco significantly more than African Americans. After experimenting with performance enhancement drugs and reaping the benefits of winning with stellar performances, many athletes do not want to stop using these substances. Hence, doping has become a problem that wreaks havoc on the world of sports.

Athletes put pressure on themselves to succeed. They take substances to relax, gain confidence mentally, and cope with all of the other pressures they are faced with while performing. Family puts pressure on an athlete because they have expectations of success, especially if a previous family member was successful in that endeavor. Likewise, competitors set the standards, and if an athlete cannot perform up to those standards the pressure is 
significant. Furthermore, athletes are vulnerable to the pressure placed on them by fans because they take the hopes and dreams of the spectators into competition with them (ASDA, 1999). If the rewards are more playing time or making the starting line up then the athlete is more likely to do what the coach says. Winning has great rewards for all who are involved, and a successful athlete means a successful coach. However, Verroken (1996) acknowledged that there is no justification for an athlete who cheats to win, and that the pressures for all athletes are the same, yet all do not resort to the use of performance enhancement drugs.

If athletes could learn that they put pressure on themselves to succeed and that it is not society putting pressure on them perhaps doping would not be such a large issue in the sport's arena. Similarly, if athletes were taught how to deal with the pressure they place on themselves they would not feel as obligated to win, but just to perform to the best of their natural ability. This is where sport psychology can help. By getting an athlete to buy into the notion that success does not mean winning, but giving it their best effort he/she will start to gain the psychological skills necessary in elite athletics. For example, Marion Jones went into the Sydney Games and was expected to win five gold medals. When she came out with less than that she still felt like she had succeeded, because she had done the best she could during that time. Thus, if more athletes looked at competition in a similar manner the use of performance enhancement drugs might decrease.

\section{Perceptions of Recreational Drug Use}

The use of drugs on college campuses is significantly related to the attitudes and behaviors that students acquired prior to the start of college (Grenier, 1993). Studies have been done looking at attitudes of young adolescents through seniors in high school regarding drug use. More specifically, these studies compare the differences in attitudes as they relate to gender, race, and socioeconomic status. 
Braxton and Yonker (1973) did a study examining the knowledge and attitudes of minority youth related to drugs. They were interested in finding out if there were significant differences in the knowledge and attitudes of poor versus affluent youth. They also looked at grade in school, gender, and race. The more education a student had the more knowledgeable he/she was about drugs. There was a significant difference in relation to socioeconomic status in that the more disadvantaged students had less measured knowledge than advantaged students. In addition, the groups with more white students had a higher measured knowledge than those with less white students. There was no significant gender difference in terms of measurable knowledge. Similarly, there were no significant differences in the attitudes about drug use. All students were concerned about illegal drug sales, would be willing to help a friend with a drug problem, and wanted stiffer jail sentences for individuals engaged in illegal drug sales.

Another investigation looked at perceived substance availability, the acceptability of drug use, and peer drug use to discover if racial differences existed among attitudes of preadolescents (Gillmore, Catalano, Morrison, Wells, Iritani, \& Hawkins,1990). The subjects consisted of 919 fifth grade students with a racial make-up of $46 \%$ White, $25 \%$ Black, and 21\% Asian American. There were $52 \%$ males and $48 \%$ females. A survey was administered to collect responses related to availability, acceptability and peer drug use. The acceptability survey consisted of six scales in which a higher score was related to a greater perceived acceptability of drug use, with two subscales having inverse scoring.

The results indicate that subjects differed by race and sex with regards to availability and acceptability, but not on peer drug use. Significant racial differences were seen in availability of marijuana, perceived parental attitude toward children drinking, and intentions to use drugs as an adult, with Whites reporting the highest acceptability in all these areas. More males than females 
intend to use drugs as adults, believe that using drugs helps make friends, and think drug use among their peers is more acceptable. The researchers also found that the belief one will get caught and punished for using drugs seemed to inhibit drug use among Blacks, but not Whites or Asian Americans. Furthermore, parental disapproval of drinking was significantly and negatively related to drug use for Asian Americans only. Thus, these findings suggest that a prevention program needs to be tailored when used for different racial groups.

Lucas and Gilham (1995) conducted a study with young adolescents of junior high school age to discover attitudes related to recreational drug use. The subjects were assessed in relation to their attitudes toward drug use and perceptions of how difficult it would be to obtain such drugs. Overall, the subjects reported conservative attitudes toward alcohol, cigarettes, and illicit drugs, with illicit drugs being slightly more prohibitive. However, females' attitudes were slightly more prohibitive than males' attitudes, and White attitudes about cigarettes were slightly more accepting than minority attitudes. Subjects did not perceive much difficulty in obtaining any of these drugs. Similar to attitudes, females perceived a little more difficulty in obtaining drugs than males. Whites also perceived more difficulty in obtaining drugs than minorities.

Roberts, Fournet, and Penland (1995) did a study with students in grades 6 through 12 to compare attitudes toward alcohol and drug use as it relates to grade, gender and ethnicity. Similar to the study conducted by Lucas and Gilham (1995), the results showed that females perceived more difficulty in buying drugs at school than did males. In addition, females believed the school provided adequate drug education and were more inclined to think that the school should provide counseling for students with drug problems. Significant differences were also seen across race. Only $25 \%$ of African American and Hispanic students thought drugs were easy to buy at school, while $40 \%$ of Asian students believed this to be true. In addition, $57 \%$ of Asian students to $68 \%$ of Hispanic 
students thought the school rules regarding drug use were strict enough, and this difference in ethnic views was statistically significant. African American and Anglo students (11\%) reported significantly lower responses to the question of whether the school provides enough drug prevention education than Hispanic or Asian students (33\%). Furthermore, not all the schools in this investigation provided any kind of drug education. According to the results, all the schools under investigation need a new program for drug education, whether it is because the current one is not sufficient or there is a lack of a program.

\section{Perceptions of Drug Testing}

Professionals in the sports' arena. There is no argument that illegal drugs and doping practices are used in college athletics. The question becomes whether or not student-athletes should be tested for these drugs. The research shows that professionals in the area of sports do not feel that drug testing is an invasion of privacy and student-athletes should be subject to drug screening (Higgins, 1995; Starkey, Abdenour, \& Finnane, 1994).

There are several issues related to drug testing of college athletes. Albrecht, Anderson, and McKeag (1992) focused on issues that are often overlooked. They included whether or not testing ensures fair play, the rationale for testing, whether student-athletes give consent to be tested, confidentiality of testing, and the expenses of testing. They argue that it is nearly impossible to ensure fair play through drug testing, because schools are unable to screen for all substances. More accurate screening techniques would need to be developed and random, unannounced, year-round testing would need to be implemented. In addition, student-athletes are often tested for recreational drugs. The rationale is that the institution is trying to protect the health of the student athletes. However, alcohol and tobacco are not tested for and they are the most compromising drugs of all.

Although student-athletes must sign a consent for testing, failure to complete the form results in ineligibility to play. Therefore, the authors argue, the athlete has no choice but to consent of he/she 
wants to continue participating and consent is obtained through coercion. Furthermore, $70 \%$ of student-athletes are not aware of the testing procedures to which they are accountable. Thus, the athletes are not fully informed. The researchers also disagree about the confidentiality of positive drug tests. If a high profile athlete is disqualified, confidentiality is almost impossible. However, many professionals believe that those who cheat should be exposed to warn other athletes. Drug testing is expensive when considering how few positive tests are obtained. It is argued though that testing is serving its purpose in deterring drug use among student-athletes (Albrecht, Anderson, \& McKeag, 1992; Starkey, Abdenour, \& Finnane, 1994).

Starkey, Abdenour, and Finnane (1994) conducted a study looking at the attitudes of athletic trainers toward drug testing of college athletes. In most cases, athletic trainers are the first source of detecting drug use in student-athletes. The majority (75.7\%) of athletic trainers surveyed believed that drug testing was not an invasion of privacy. In addition, there was little agreement that targeting student-athletes rather than the student body was discriminatory. Those not involved in the drug screening process felt that testing only student-athletes was discriminatory. Eighty-two percent of the trainers surveyed also said they would submit to a drug test as a prerequisite for employment.

The athletic trainers surveyed strongly agreed that educational sessions should be a large part of the drug testing process. Additionally, the trainers felt that educational sessions needed to be reinforced by actually screening the athletes. Only $29.5 \%$ of the athletic trainers surveyed thought their programs were very effective. Fifty-eight percent rated their programs as somewhat effective, while $10.6 \%$ gave their programs a rating of not effective. Drug screening programs was the only area in which the researchers found a significant gender difference. Females disagreed more than males with the idea that drug screening programs are only effective in the season in which they are done. 
Another gender difference was that male athletic trainers felt that being involved in the drug testing process compromised their relationship with the athletes.

Higgins (1995) surveyed six different university populations, which included faculty, faculty/staff, athletic staff, nonathletic staff, student-athletes, and nonathlete students about their perceptions and attitudes related to drug testing of college student-athletes. The researcher wanted to know if differences existed for each population and if differences could be seen based on age, gender, and ethnicity. The instrumentation involved a survey designed by the researcher and given to a panel of experts to determine face validity, functional reliability, and usability of the survey. No psychometric coefficients are given. Thus, more research needs to be done in order to validate the results of this study.

The results of the survey indicate that a strong majority of student-athletes $(85.5 \%)$, nonathlete students $(77.9 \%)$ and athletic staff $(69.3 \%)$ agree with the drug testing of student-athletes. Furthermore, $52.3 \%$ of faculty/staff agreed with the drug testing of student athletes, while the faculty had the largest percentage of disagreement at 32.9\%. With regards to student-athletes being tested prior to competition, $53.9 \%$ of faculty, $63.6 \%$ of faculty/staff, $50 \%$ of athletic staff, and $46.5 \%$ of nonathletic staff disagreed, while only $38.6 \%$ of student-athletes and $36.9 \%$ of nonathletes disagreed with this practice. The majority of athletic staff (66.7\%), nonathletic staff (53.4\%), student-athletes (64.1\%), and nonathletes $(65.9 \%)$ thought student-athletes should be tested at random. Similar results were found as to whether student-athletes should be tested on suspicion of drug use. The only difference was that the majority of the faculty (55.4\%) also agreed.

There were three ideas that all subgroups agreed with. The first is that all drug testing samples should be collected in front of a witness, with the highest percentage of agreement seen in studentathletes $(89.6 \%)$. The second is that all subgroups were in favor of checking initial drug tests with a 
different method if the subject wants to check for a false positive. One hundred percent of the athletic staff agreed with the idea of having a second testing method. The last idea is concerned with the consequences of failing a drug test. All populations disagreed that a student-athlete should be automatically cut from the team. However all agreed that some action should be taken, such as a drug-counseling program or suspension from the team until counseling is undergone. With regards to allowing the public availability of test results, those subgroups in the field of athletics agreed more than those outside of athletics, with $55.6 \%$ of athletic staff and $67.1 \%$ of student-athletes agreeing and only $40.4 \%$ of faculty and $27.2 \%$ of faculty staff agreeing. Three influences on attitudes regarding drug testing of student-athletes emerged. They are constitutional rights, health and safety, and the integrity of college sport.

Differences were also seen across the demographic variables of age and gender. Over $80 \%$ of participants under 25 years believed that student-athletes should be drug tested. The percentages decreased as the age of participant increased. A similar pattern is seen with this age group having the highest percentage of agreement with the idea that student-athletes should be tested prior to competition. In addition, a higher percentage of those 25 and under thought that student-athletes should be suspended from the team until the completion of a drug-counseling course if they test positive. There was a significant difference in factors contributing to attitudes about drug testing across age groups. The groups that were 20 years and younger, 21 to 25 years, and 26 to 35 years felt the integrity of college sport and fair competition influenced their attitudes, while groups that were 36 to 45 years, 46 to 55 years, and 56 years and older felt constitutional rights and health and safety influenced their attitudes. A reason that the younger age groups may be in more agreement with drugs testing, strict punishment for a positive test, and the large influence the integrity of college sport played in their perceptions is the amount of exposure these individuals have received regarding doping 
in sport. The younger generations have seen more media coverage related to doping in sport than the older generations. Furthermore, because of greater media coverage the sports' heroes of today, which the younger generation may follow more closely than the older generation, are exposed for using drugs more often than heroes past.

There were only a few significant gender differences in response to perceptions and attitudes related to drug testing of student-athletes. More males than females thought testing results should be made available to the athletic department, while more females agreed that drug testing should include all illegal drugs and alcohol. However, more females than males disagreed that student-athletes should have all financial aid removed after a single positive test. Interestingly, no significant differences were seen across ethnic backgrounds. As a result of this research, it seems as though those involved closely with athletics agree with the idea of drug testing, and they have a more positive attitude towards it.

Athletes' perceptions. Drug testing is one method of trying to eliminate the use of performance enhancement drugs in sport. It is argued that because so few athletes test positive for banned substances, testing is serving its purpose as a deterrent to drug use (Albrecht, Anderson, \& McKeag, 1992). However, experts say that the levels of testing for many drugs are so high that an athlete can take a substance and easily pass a urine drug test, which is what is used in college athletics (Clark \& Milliken, 2000). Many athletes think testing should be more widespread and occur more often. Moreover, of those athletes survey, $82 \%$ want stricter controls on drug use during competition and training (MacAuley, 1996).

Though it seems drug use in sport is growing, most athletes welcome drug testing and believe it is something an athlete must do in order to compete (Diacin, 1999). In addition, Schneider and Morris (1993) found that only $17 \%$ of the athletes surveyed thought drug testing was an invasion of 
privacy. Participants in Diacin's (1999) study of in-depth interviews with student-athletes perceived athletes as a representative of their schools, and, so, should accept reduced amounts of privacy, because they have committed to a higher standard. The participants agreed that an athlete has a choice to play, and by choosing to play they are agreeing to drug testing. However, the researchers found that the participants believed if an athlete passed a drug test, he/she should not have to take multiple tests. These athletes also thought athletes should be tested for performance enhancing and recreational drugs. In addition, these athletes believed fairness was the primary reason drug testing should occur.

Hamilton and Stone (1990) found similar results regarding college students' and student athletes' attitudes toward drug testing of college athletes. The major of the students (87.1\%) and student-athletes (79\%) felt that institutions had a right to do drug testing. In addition, at least $95 \%$ of the respondents believed drug testing resulted in safer competition. The results also show that over $88 \%$ of the participants agreed that it was a college athlete's duty not to take illegal drugs.

Research on attitudes related to drug testing has been done looking specifically at college football players. More than likely it is because this population of college athletes is targeted most with regards to illegal doping (Helduser \& Bechtol, 1989). Helduser and Bechtol (1989) surveyed a Southwest Texas football team, because so often the athletes asked about their rights and inquire if testing was an invasion of privacy. Over half of the football players surveyed (58\%) thought that mandatory drug testing was an invasion of privacy. In contrast, $75 \%$ of these football players felt that drug testing would reduce the use of drugs on the team and that drug testing should be required. Although these athletes think drug testing should be required in order to reduce drug use, the involuntary nature of the drug testing is seen as an invasion of privacy. However, $60 \%$ of the players said they would volunteer for drug testing even if it was not mandatory and had confidence in the 
accuracy of the results. If a repeated positive test was obtained, $67 \%$ of the players agreed with a dismissal policy.

Corresponding results were found in a study done by Abdenour, Miner, and Weir (1987). Sixty-three percent of the football players surveyed believed that drug testing was a good deterrent to drug use. Additionally, $51 \%$ of the athletes indicated that knowing their teammates were not taking drugs improved the team's performance. However, suspension from the team for a positive test was only supported by $49 \%$ of the players. The majority of the players $(75 \%)$ thought that individuals testing positive should be required to go to counseling. Yet, the players did not feel that counseling alone would deter drug use, but counseling in combination with drug testing would.

Gender and sport differences. A few studies have looked at areas in which differences in attitudes related to drug testing exist. A study looking at the gender differences in attitudes of college athletes about drug use and drug testing completed by Issari \& Coombs (1998) found male athletes to significantly differ from females in their attitudes regarding drug testing. The researchers discovered that more males than females agreed that drug testing as an invasion of privacy. Similar results are seen with drug testing being a violation of civil rights in that more males than females agree. The results also show that more males than females agree that testing is unethical. In contrast, more females were in favor of drug testing during routing physical exams than males. Furthermore, woman were more likely to favor testing of all those involved in the sports arena, while men were more in favor of testing all college students. When a positive test is obtained, significantly more women thought the athlete should be banned from the team, whereas men thought athletes should be given two or more chances after a positive test. Thus, women held a more positive attitude than men regarding drug testing. 
Schneider and Morris (1993) conducted a study to find out if attitudes of college athletes about drug testing differed across gender and sport. The researchers surveyed 12 varsity athletic teams (six male, six female). Seventy-two percent of the respondents were male, and $28 \%$ percent were female. Few significant differences were found. However, $56 \%$ of the athletes thought drug testing discouraged drug use and felt athletes should be notified prior to their test date. Yet only $48 \%$ of the athletes surveyed believed random drug testing was necessary. There was only one case in which teams significantly differed regarding attitudes toward drug testing. The question was whether the penalty for a positive test was severe enough. Soccer players (41\%) disagreed that penalties were severe enough, while no basketball players disagreed, and felt the penalties for a positive drug test were severe enough. There was also only one significant gender difference in that males agreed more than females that all sports should be tested equally. According to the differing results in the research on gender differences, no concrete conclusions can be drawn with regards to males' and females' attitudes toward drug testing of college athletes.

\section{Perceptions of Doping in Sport}

General public. Sports' fans want their athletic heroes to be clean. They want to be inspired by natural human performance, not figure out how much a substance an athlete would have had to take to become the fastest human in the world (Denham, 1999). With all the publicity that drug use got in the Sydney Olympics, spectators do not know whom to trust. They start to ask, "Are they all tainted?" (ESPN, 2000).

Paccagnella and Grove (1997) conducted an investigation looking at the attitudes undergraduate students had of steroid use. The participants associated athletes that used drugs as significantly less honest and less rule oriented than other performers that had negative stigmas attached to them such as criminal activity and sexual issues. More males than females viewed athletes 
that used steroids as more uncaring and lacking self-control. However, there was no significant difference on friendliness of the athletes, whether they used drugs or not. It was concluded that the participants may have a strong expectation for sportsmanship and fair play and violation of this results in a disappointing view of the athletes.

Nocelli, Kamber, Francois, Gmel, and Marti (1998) conducted a study in Switzerland looking at the public's perception of doping in elite and recreational sports. The Swiss population sees doping as significantly more of a problem in elite athletics (84.1\%) than recreational athletics (44.3\%). The most important problems associated with doping were the perceived threats to physical health (84.5\%), ethics and morals (74.7\%), an equal opportunity to win (70.5\%), and mental health (68.7\%). A gender effect was seen with regards to problems associated with doping in sport. More women felt the use of performance enhancement drugs was a threat to mental health. Over $90 \%$ of the respondents believed doping was used to enhance physical performance, while only $60 \%$ thought doping was used to improve physical appearance. Overall, it was found that doping in sport was an important issue because it was such a widespread problem.

Professionals in the sports' arena. The often-asked question is whether or not coaches and those involved in sports organizations condone the use of drugs among athletes. Many times an athlete is not completely aware of what he is putting in his body. For example, Ben Johnson, a Canadian sprinter, was stripped of his gold medals at the 1988 Seoul Olympics for the use of anabolic steroids. However, Johnson claims he was not sure exactly what he was taking; only that he was following the instruction of his coach (Voy, 1991). This happens to many athletes, and they still receive a negative stigma from fans and fellow athletes alike.

Anshel (1991b) wrote an article about the role coaches and sport organizations play with regards to doping in sport. In his opinion, these individuals promote drug use. For example, coaches 
often send a message to their athletes saying, "Do what you have to do to win." If this means taking performance-enhancing drugs, so be it. In addition, after a professional cyclist tested positive, the U.S. Professional Cycling chief executive only imposed a three-month ban, which supports the accusations that sports leaders and administers simply wink at international and organizational sanctions banning drug use in sport.

Despite the fact that many coaches and organizations are involved in doping in sport, research shows that the majority of these individuals do not condone drug use. Seventy-eight percent of physical education teachers surveyed thought steroid use was cheating and opposed the spirit of the game (Levy \& Ferrone, 1993). Another study found that respondents, including coaches and sports medicine personnel, did not favor steroid use and agreed with all items worded negatively toward steroid use (Floyd, Wholeben, Cummings, \& Lawson, 1993). However, fewer coaches than expected by chance agreed that it was unfair to improve performance through steroid use. Less sports medicine personnel than expected disagreed that coaches put pressure on their athletes to use steroid. Yet, sports medicine personnel agreed that coaches ignore steroid use on their team and would not sacrifice performance to stop steroid use, while athletes disagreed. In addition, more males than females agreed that coaches ignore steroid use on their team. While the attitudes toward steroid use appear to be negative, differences among those in the sports' arena continue to exist.

Fjeldheim (1992) found that $100 \%$ of sports instructors and sports leaders surveyed in Norway believed it was the responsibility of instructors and leaders to prevent doping. In addition, $92 \%$ of the participants felt that instructors and leaders could directly or indirectly further the use of doping in sport. In the same study, $98 \%$ of respondents agreed that doping is cheating. Ninety-seven percent of instructors and leaders thought drug controlling procedures should be conducted during training and disagreed that doping should be allowed because winning was important. The majority of 
respondents $(81 \%)$ also disagreed that punishments were too strict if caught doping. Although the majority of instructors and leaders agreed that doping improves performance, they knew it had negative and damaging physical and mental side effects.

In a study surveying NCAA coaches and trainers, results show that over $90 \%$ coaches and trainers disagree with the use of amphetamines, sedatives, and steroids by male college athletes (Meylink \& Struck, 1976). Even if drugs were available to all athletes and no physical danger was involved, over $75 \%$ of the respondents thought drug use was unethical. Conversely, $80 \%$ of those surveyed felt that drugs should not be used during competition, while only $50 \%$ disagreed with the use of drugs to aid recovery from competition. In addition, $87 \%$ of participants thought that an athlete should be able to use a drug and compete if it arrests a physical condition such as asthma or emphysema. Seventy-four percent of coaches and trainers surveyed felt that the greater the emphasis is on competition and winning the more athletes used drugs.

McCallister (1989) conducted a study looking at the attitudes of athletic directors, athletic trainers, and coaches about the use of drugs in sport. Forty-nine percent of the participants thought that $10-25 \%$ of college athletes were involved in doping. Half of the respondents believed that these athletes starting using drugs in junior high, while only 5\% felt drug use started in college. When comparing team and individual sports, $67 \%$ of athletic directors, athletic trainers, and coaches surveyed thought drug use was most prevalent in team sports, with only $19 \%$ believing drug use was most prevalent in individual sports. The majority of respondents $(89 \%)$ felt males had the highest percentage of drug use in college athletics. There were no significant differences in the attitudes of athletic directors, athletic trainers, and coaches based on occupation or gender. In addition, there was no significant difference in the attitude of coaches based on gender of athletes coached. However, there was a significant difference in coaches' attitudes based on type of sport in that coaches of 
individual sports more strongly favored the use of drugs in college athletics. The attitude of an individual sport coach may agree more with drug use in college athletics because he/she may have one star athlete that can compete at the next level with the use of performance enhancement drugs. In general, professionals involved in the sports' arena do not condone doping and believe it is unethical and results in unfair competition.

Athletes' perceptions. Many athletes perceive certain rewards, such as enhanced physical and psychological functioning, enhanced social recognition, and enhanced vocational functioning, as justification for the use of steroids. Fuller and LaFountain (1987) found that athletes using steroids believed they were not harming anyone, and serious athletes were required to use steroids to be competitive. However, they also said that if those they competed against did not use steroids, they would consider not using steroids as well. Floyd et al (1993) found that $79 \%$ of athletes surveyed would not use steroids if there were random drug testing before games. Still, many young athletes see steroid use as a nutritional supplement (Breo, 1990). Athletes also thought steroid use was associated with having a dedicated attitude and a willingness to sacrifice to succeed (Fuller \& LaFountain, 1987).

Elite athletes surveyed admitted that taking drugs makes them feel better about themselves and have more confidence (Anshel 1991a). Thirty-two and half percent of these took drugs because of the fear of failure, which was twice as high for women than men. Of the 126 athletes involved in the study, ten believed that taking steroids was due to a sense of adventure or thrill, and did not feel impervious to any negative side effects. Similarly, $10.3 \%$ of the respondents felt drugs improved aggression, mostly in contact sports, and helped escape a dangerous or uncertain situation like a difficult competitor. The majority of the respondents (57.1\%) thought that the media and popular sports stars established drug use in intercollegiate athletics, because many college athletes aspire to 
compete at a higher level. Lastly, many athletes believe they will not get caught, and continue to use drugs to improve performance.

Nutter (1997) conducted a study examining the attitudes of middle school students about steroid use. Only 9 of 265 students used steroids. Of the users, 7 were sports participants, and thought using steroids would increase athletic performance. Less than one percent of the students felt steroids were necessary to succeed in sports. In addition, $59.6 \%$ of the individuals agreed that steroids were harmful, with white boys viewing them as more harmful than "other" boys. However, $25 \%$ of the respondents believed steroids would help performance.

A study looking at the attitudes of high school students and doping in sport revealed that doping was viewed as unacceptable (Kindlundh et al, 1997). In addition, Tangen and colleagues (1997) found that $67 \%$ of athletes surveyed agreed that doping was unacceptable. Sixty-five percent of the athletes not using drugs thought there was nothing to be gained by using drugs. In both studies a majority of respondents believed athletes take drugs to improve appearance and enhance performance.

Anshel and Russell (1997) conducted a study with international level athletes regarding their perceptions and knowledge about doping in sport. The researchers found that international level athletes have significantly more positive attitudes toward drug use in sport than national, state, or local level athletes. In addition, international level athletes had greater knowledge about drug use in sport. Thus, there was no relationship between level of knowledge and more negative views of doping in sport. It could be argued that the more an athlete knows about doping in sport and the benefits that can result rather than the harm it can do, the more he/she can identify with the improvements in performance. Therefore, the athlete may be more likely to become involved in drug use. 
Attitudes regarding painkilling drugs in sport are slightly different than attitudes regarding performance enhancement drugs in sport. Tricker (2000) found that 29\% of student athletes surveyed thought there was nothing wrong with taking painkilling drugs on the day of competition to prevent pain during competition. Furthermore, 33\% of respondents felt that painkilling drugs were necessary to recover from participation. Likewise, another study found that athletes generally agree with using anti-inflammatories during and out of season in response to injury, while they generally disagreed with the use of steroids (Floyd et al, 1993).

Although many athletes may believe drugs are their last resort to better performance, like the general population, most do not condone the use of performance enhancement drugs. In "Athletes and drugs" (1992), many athletes were discouraged about the widespread use of performance strategies like blood doping and the use of anabolic steroids and human growth hormone. They recommended holding two Olympics: one drug-induced and another for clean athletes. The general belief among elite athletes is that most Olympians in the world are using performance enhancement drugs and very few are performing naturally. Commentators believe that an athlete gains unfair advantages with the use of drugs. They want to see natural talent determine the winner, not some artificial means (Black \& Pape, 1997).

Most athletes do not look up to those that succeed because of the use of performance enhancement drugs. Paccagnella and Grove (1997) concluded that athletes have a strong regard for sportsmanship and fair play, and a violation of these values through the use of performance enhancing drugs is a disappointment to the world of sports. In contrast, Diacin (1999) found that athletes perceived the denial of an athlete to compete because of the necessary use of banned substances (i.e. asthma medication) as unfair. Thus, there may be certain circumstances where athletes feel that the use of performance enhancement drugs is justified and unjustified. 
Gender and sport differences. Athletes of different gender and sport perceive the use of performance enhancement drugs differently. Pan and Baker (1998) found that female athletes associated the use of performance enhancement drugs with the attributes of perceived dysfunction (risks), perceived function (benefits), social factors, and athletic relevance. However, male athletes only associated performance enhancement drug use with the attributes of perceived dysfunction and athletic relevance. This means that females associate steroid use with increased health risks, increased pleasure, increased societal attention, and increased athletic performance, while males only associate steroid use with increased health risks and increased athletic performance. The significant difference between contact and non-contact sports was in the perception of steroid use. Athletes who participated in non-contact sport did not see steroids to be highly athletically relevant. Thus, the researchers concluded that the structure of a sport might articulate an athlete's perceptions toward performance enhancement drug use in sport.

Several other studies reported similar results in that females view doping more negatively than males (Floyd et al, 1993; Kindlundh et al, 1997; Tricker, 2000). Floyd et al, found that more females than males agreed that steroids had a dangerous effect on body functions. In addition, more females than males disagreed that is was acceptable to use steroids to win a championship or earn a scholarship, that athletes must use steroids to stay competitive, or that there are benefits of steroids. The gender difference is seen with painkilling drugs as well. Male athletes were significantly more likely to agree that there is nothing wrong with using painkilling drugs on the day of competition to prevent pain.

Conclusion

The review of literature included the history of doping in sport, doping in modern athletics, use of drugs and doping, perceptions of recreational drug use, perceptions of drug testing, and perceptions of doping in sport. The overall findings of the research indicate that doping in sport has 
been around since the beginning of sport competition. In addition, the use of drugs in sport continues to grow through the years. The research also shows the differences that exist among individuals that use drugs, including gender, race, socioeconomic status, and type of sport. By and large, individuals, athletes and non-athletes, support drug testing and do not condone drugs or doping in sport.

Very few studies have been conducted looking at the perceptions of college athletes regarding the use of performance enhancement drugs. However, it is known that most athletes do not agree with the use of banned substances in a competitive atmosphere, and they want fair play. Thus, the majority of athletes are in favor of drug testing to ensure fair competition. In addition, athletes using performance enhancement drugs to win are looked down upon by everyone, including the public, professionals in the sports' arena, and fellow athletes.

While the trend seems to be that males are more accepting of doping in sports than females, there is not a lot of researcher that displays differences among sport groups. Furthermore, there is no research looking at the gender or socioeconomic status of the athlete with regards to perceptions about doping in sport. All four of these factors may have an influence on how an athlete perceives the role of drugs in sport. In addition, it may change how drug education programs are run for incoming college athletes, by structuring them based on the perceptions different athletes have toward doping in sport. Therefore, it is important to conduct a study that looks at all four of these variables in order to gain the proper perspective on how to deter doping in sport. 


\section{REFERENCES}

Abdenour, T. A., Miner, M. J., \& Weir, N. (1987). Attitudes of intercollegiate football players toward drug testing. Athletic Training, 22(3), 199-201.

Abell, V. L. (Ed.). (2000). 2000-2001 NCAA Division I Manual. Indianapolis, IN: NCAA. Albrecht, R. R., Anderson, W. A., \& McKeag, D. B. (1992). Drug testing of college athletes. Sports Medicine, 14(6), 349-352.

Anshel, M. (1991a). A survey of elite athletes on the perceived causes of using banned drugs in sport. Journal of Sport Behavior, 14(4), 283-307.

Anshel, M. (1991b). Do coaches and sport organisations condone drug use among athletes.

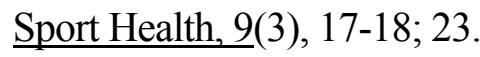

Anshel, M. H. \& Russell, K. G. (1997). Examining athletes' attitudes toward using anabolic steroids and their knowledge of the possible effects. Journal of Drug Education, 27(2), 121-145.

Anshel, M. H. (1998). Drug Abuse in Sport: Causes and Cures. In J.M. Williams (Ed.), Applied Sport Psychology (pp. 372-397). Mountain View, CA: Mayfield Publishing Co.

Athletes and drugs: a separate pace. (1992). Psychology Today, 25(4), 52-53.

Australian Sports Drug Agency. (1999). ASDA Drugs in Sport. Sydney, Australia. Retrieved September 8, 2000, from the World Wide Web: http://www.ausport.gov.au/asda/drugsin.html.

Barnard, M. (1998, September 25). Drugs and darwin fuel athletes. New Statesman, $\underline{127}(4404), 48-49$.

Beresford, H. R. (1989). Legal considerations. In G.I. Wadler \& B. Hainline (Eds.), Drugs and the athlete (pp. 234-246). Philadelphia: F.A. Davis Company. 
Black, T. \& Pape, A. (1997). The ban on drugs in sports. Journal of Sport and Social Issue, $\underline{21}(1), 83-92$.

Braxton, E. R. \& Yonker, R. J. (1973). Does being urban, poor, black, or female affect youth's knowledge and/or attitudes relating to drugs? Journal of School Health, 43(3), 185-188.

Breo, D. L. (1990). Of MDs and muscles-lessons from two retired steroid doctors. JAMA, $\underline{263}(12), 1697-1705$.

Clark, K. \& Milliken, R. (2000, August 14). Positive on testing. U.S. News and World Report, 129(6), 40-41.

Denham, B. E. (1999). On drugs in sports in the aftermath of flo-jo's death and big mac's attack. Journal of Sport and Social Issue, 23 (3), 362-367.

Diacin, M. (1999). Perceptions of male intercollegiate athletes on performance enhancement substances in sport. Unpublished master's thesis, Bowling Green University, Bowling Green.

ESPN. (2000, October 1). Are athlete's rights more important than clean competition? Outside the Lines. Available: http://www.espn.go.com/tvlistings/show27transcript.html.

Fjeldheim, T. B. (1992). Sports instructors and sports leaders: attitudes toward doping in sports. Collegium Antropologicum, 16(2), 343-348.

Floyd, J. D., Wholeben, B. M., Cummings, C. C., \& Lawson, J. D. (1993). Attitudes toward steroids in amateur athletics: coaches, students, and officials. Illinois Journal for Health, Physical Education, Recreation, and Dance, 34, 8-14.

Ford, P. (2000, November 6). Tolerance of sports doping on trial in France. Christian Science Monitor, 92(241), 1.

Fuller, J. R. \& LaFountain, M. J. (1987). Performance-enhancement drugs in sport: a different form of drug abuse. Adolescence, XXII(88), 969-976. 
Gillmore, M. R., Catalano, R. F., Morrison, D. M., Wells, E. A., Iritani, B., \& Hawkins, J. D. (1990). Racial differences in acceptability and availability of drugs and early initiation of substance use. American Journal of Drug and Alcohol Abuse, 16(3-4), 185-206.

Graham, N. (1996). The influence of predictors on adolescent drug use. Youth and Society, $\underline{28}(2), 215-235$.

Green, G. A. \& Puffer, J. C. (1997). Drugs and doping in athletes. In M. B. Mellion, W. M. Walsh, \& G. L. Shelton (Eds.), The team physicians handbook (pp. 212-238). Philadelphia: Hanley \& Belfus.

Green, G. A., Uryasz, F. D., Petr, T. A., \& Bray, C. D. (2001). NCAA study of substance use and abuse habits of college student-athletes. Clinical Journal of Sports Medicine, 11(1), 51-56.

Grenier, C. (1993). A substance abuse survey analysis of LSU students: profiles and correlates, spring 1991. Journal of Adolescent Chemical Dependency, 2(3-4), 93-129.

Hamilton, L. S. \& Stone, R. W. (1990). Student attitudes toward drug testing of college athletes. Physical educator, 47(2), 33-36.

Heldusor, B. \& Bechtol, W. (1989). Attitudes about drug testing: what tested athletes think. Texas Coach, 33(9), 25-26.

Hendrickson, T. P. and Burton, R. W. (2000). Athletes' use of performance enhancement drugs. In D. Begel and R. W. Burton (Eds.), Sport psychiatry (pp. 142-56). New York: W. W. Norton \& Co.

Higgins, K. J. (1995). A survey of the perceptions, attitudes, and relationships of five different university populations concerning the drug testing of college student-athletes. Unpublished doctoral dissertation, Temple University, Philadelphia. 
Hollingshead \& Redlich. (1958). Social Class and Mental Illness. New York: John Wiley \& Sons, Inc.

Issari, P. \& Coombs, R. H. (1998). Women, drug use, and drug testing. Journal of Sport and

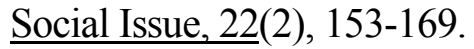

Ivy, J. L. (1983). Amphetamines. In M.H. Williams (Ed.), Ergogenic aids in sport (pp. 101127). Champaign, IL: Human Kinetics Publishers, Inc.

Kindlundh, A. M. S.; Isacson, D. G. L., Berglund, L., \& Nyberg, F. (1997). Doping among high school students in Uppsala, Sweden: a presentation of the attitudes, distribution, side effects, and extent of use. Scandinavian Journal of Social Medicine, 26(1), 71-74.

King, N. D. (1991). Drugs in sport: the development of an instrument to determine the knowledge, behavior, and attitudes of college athletes about sport-performance drugs and sport-coping drugs. Unpublished doctoral dissertation, University of Kansas, Lawrence, Kansas.

Kuhn, C.; Swartzwelder, S.; and Wilson, W. (1998). Buzzed. New York: W. W. Norton \& Co.

Kuhn, C.; Swartzwelder, S.; and Wilson, W. (2000). Pumped: Straight facts for athlete about drugs, supplements, and training. New York: W. W. Norton \& Co.

Levy, J. \& Ferrone, C. (1993). A survey of attitudes toward adolescent anabolic steroid use by physical education teachers. CAHPER Journal, 59(4), 31-33.

Lucas, W. L. \& Gilham, S. A. (1995). Profiles of drug use and attitudes among young adolescents. Journal of Child and Adolescent Substance Abuse, 4(3), 41-60.

MacAuley, D. (1996). Drugs in sport. Student British Medical Journal, 4(44), 321-326.

McCallister, S. G. (1989). Selected attitudes of college athletic directors, athletic trainers, and coaches toward the use of ergogenic aids in college athletics and the current status of ergogenic aids 
use in college athletic programs. Unpublished doctoral dissertation, University of Arkansas, Fayetteville, Arkansas.

Meylink, W. D. \& Struck, P. J. (1976). Opinion of NCAA coaches and trainers toward the use of ergogenic drugs (Report No. SP010044). Wyoming University, Laramie, Wyoming: Teacher Education. (ERIC Document Reproduction Service No. ED 121 779)

Mirken, G. \& Hoffman, M. (1978). The sportsmedicine book. Boston: Little, Brown.

Mish, F. C. et al. (Ed.). (1989). Webster's Ninth New Collegiate Dictionary $\left(9^{\text {th }}\right.$ ed.). Springfield, MA: Merriam-Webster, Inc.

NCAA Self-Study Report 1999-2000: West Virginia University. (2000). Indianapolis, IN: NCAA.

Nocelli, L., Kamer, M., Francois, Y., Gmel, G., \& Matri, B. (1998). Discordant public perception of doping in elite versus recreational sport in Switzerland. Clinical Journal of Sport Medicine, 8(3), 195-200.

Nutter, J. (1997). Middle school students' attitudes and use of anabolic steroids. Journal of Strength and Conditioning Research, 11(1), 35-39.

O’Brien, R. \& Kennedy, K. (1998, August 3). Is everybody doing it? Sports Illustrated, $\underline{89}(5), 30-33$.

Olrich, T. W. \& Ewing, M. E. (1999). Life on steroids: bodybuilders describe their perceptions of the anabolic-steroid use period. The Sport Psychologist, 13, 299-312.

Paccagnella, M. \& Grove, J. R. (1997). Drugs, sex, and crime in sport: an australian perspective. Journal of Sport and Social Issue, 21(2), 179-188.

Pan, D. W. \& Baker, J. A. W. (1998). Perceptual mapping of banned substances in athletics. Journal of Sport and Social Issue, 22(2), 170-182. 
Parker, K. D. \& Weaver, G. (1995). Predictors of alcohol and drug use: a multi-ethic comparison. Journal of Social Psychology, 135(5), 581-590.

Roberts, T. G., Fournet, G. P., \& Penland, E. (1995). A comparison of the attitudes toward alcohol and drug use and school support by grade level, gender, and ethnicity. Journal of Alcohol and Drug Education, 40(2), 112-127.

Schneider, D. \& Morris, J. (1993). College Athletes and drug testing: attitudes and behaviors by gender and sport. Journal of Athletic Training, 28(2), 146-150.

Starkey, C., Abdenour, T., \& Finnane, D. (1994). Athletic trainers attitudes toward drug screening of intercollegiate athletes. Journal of Athletic Training, 29(2), 120-122.

Tangen, J. O, Bergsgard, N. A., Barland, B., \& Breivik, G. (1997). To dope or not to dope: a study on the decision to use drugs in Norwegian sports. Corpus, Psyche et Societas, 4(1), 41-65.

Tricker, R. (2000). Painkilling drugs in collegiate athletics: knowledge, attitudes and use of student athletes. Journal of Drug Education, 30(3), 313-324.

Verroken, M. (1996). Drugs use and abuse in sport. In D.R. Mottram (Ed.), Drugs in sport (pp. 18-55). London: E \& FN Spon.

Voy, R. (1991). Drugs, sport, and politics. Champaign, IL: Leisure Press.

Webster, W. J. (1973). Trends in reported drug usage among public school children. Journal of Experimental Education, 42(2), 80-86.

Williams, M. H. (1989). Beyond training: how athletes enhance performance legally and illegally. Champaign, IL: Leisure Press. 
TABLE 1

Descriptive Demographic Data of

College Student - Athlete Sample $(\underline{N}=93)$

\begin{tabular}{|c|c|c|c|c|}
\hline Participants & $N$ & $\begin{array}{c}\text { Race } \\
\text { (Caucasian/Non- } \\
\text { Caucasian) } \\
N\end{array}$ & $\begin{array}{c}\text { Socioeconomic } \\
\text { Status } \\
\text { (high/low) } \\
N\end{array}$ & $\begin{array}{c}\text { Sport } \\
\text { (Team/Individual) } \\
(1 \mathrm{missing}) \\
N\end{array}$ \\
\hline $\begin{array}{l}\text { College Student } \\
\text { Athletes }\end{array}$ & 93 & $\begin{array}{l}\text { Caucasian }=76 \\
\text { Non-Caucasian }=17\end{array}$ & $\begin{array}{l}\text { High }=52 \\
\text { Low }=41\end{array}$ & $\begin{array}{l}\text { Team }=58 \\
\text { Individual }=34\end{array}$ \\
\hline Male & 65 & $\begin{array}{l}\text { Caucasian }=54 \\
\text { Non-Caucasian }=11\end{array}$ & $\begin{array}{l}\text { High }=34 \\
\text { Low }=31\end{array}$ & $\begin{array}{l}\text { Team }=42 \\
\text { Individual }=22\end{array}$ \\
\hline Female & 28 & $\begin{array}{l}\text { Caucasian }=22 \\
\text { Non-Caucasian }=6\end{array}$ & $\begin{array}{l}\text { High }=18 \\
\text { Low }=10\end{array}$ & $\begin{array}{l}\text { Team }=16 \\
\text { Individual }=12\end{array}$ \\
\hline
\end{tabular}

TABLE 2

Demographic Data of College Student Athletes

Compared to the Institution Population

\begin{tabular}{|c|l|l|l|}
\hline Population & $\begin{array}{c}\text { Gender } \% \\
(\text { Male/Female })\end{array}$ & $\begin{array}{c}\text { Race } \% \\
(\text { Caucasian/Non- } \\
\text { Caucasian })\end{array}$ & $\begin{array}{c}\text { Sport \% } \\
(\text { Team/Individual })\end{array}$ \\
\hline $\begin{array}{c}\text { Participants } \\
(\underline{N}=93)\end{array}$ & Male $=69.9$ & Caucasian $=81.7$ & Team $=62.4$ \\
\hline $\begin{array}{c}\text { All Student } \\
\text { Athletes } \\
(\underline{N}=524)\end{array}$ & Male $=61.0$ & Caucasian $=73.4$ & Team $=59.9$ \\
\hline $\begin{array}{c}\text { Entire Student } \\
\text { Body* } \\
(\underline{N}=15,463)\end{array}$ & Male $=54.0$ & Non-Caucasian $=26.6$ & Individual $=40.1$ \\
\hline
\end{tabular}


TABLE 3

Principal Components Factor Analysis (varimax rotation) Of Subjects' Responses to the KDSQ $(\underline{N}=93)$

\begin{tabular}{|c|c|c|c|}
\hline DRUG & ITEMS & Factor A & Factor B \\
\hline \multirow[t]{10}{*}{ Alcohol } & 1 & .37 & .00 \\
\hline & 2 & .25 & .39 \\
\hline & 3 & .12 & .45 \\
\hline & 4 & .19 & .30 \\
\hline & 5 & .35 & .34 \\
\hline & 6 & .39 & .26 \\
\hline & 7 & .45 & .12 \\
\hline & 8 & .00 & .12 \\
\hline & 9 & .24 & .49 \\
\hline & 10 & .34 & -.27 \\
\hline \multirow[t]{2}{*}{ Smokeless Tobacco } & 1 & .240 & .241 \\
\hline & 2 & .00 & .22 \\
\hline \multirow[t]{9}{*}{ Stimulants } & 1 & .63 & .24 \\
\hline & 2 & .00 & -.24 \\
\hline & 3 & .42 & .00 \\
\hline & 4 & .52 & .16 \\
\hline & 5 & .53 & .12 \\
\hline & 6 & .68 & .36 \\
\hline & 7 & .47 & .36 \\
\hline & 8 & .00 & .00 \\
\hline & 9 & -.25 & -.15 \\
\hline \multirow[t]{6}{*}{ Human Growth Hormone } & 1 & .73 & .25 \\
\hline & 2 & .21 & .00 \\
\hline & 3 & -.26 & -.20 \\
\hline & 4 & .58 & .23 \\
\hline & 5 & -.41 & -.26 \\
\hline & 6 & .00 & -.33 \\
\hline \multirow[t]{7}{*}{ Marijuana } & 1 & .00 & -.37 \\
\hline & 2 & .35 & .65 \\
\hline & 3 & .00 & .72 \\
\hline & 4 & .15 & .77 \\
\hline & 5 & .15 & .80 \\
\hline & 6 & .24 & .18 \\
\hline & 7 & .00 & -.45 \\
\hline \multirow[t]{13}{*}{ Steroids } & 1 & .74 & .17 \\
\hline & 2 & .50 & .36 \\
\hline & 3 & .45 & .40 \\
\hline & 4 & .71 & .37 \\
\hline & 5 & .40 & .18 \\
\hline & 6 & .63 & .26 \\
\hline & 7 & .50 & .37 \\
\hline & 8 & .73 & .33 \\
\hline & 9 & .78 & .24 \\
\hline & 10 & -.35 & -.29 \\
\hline & 11 & -.45 & -.31 \\
\hline & 12 & -.69 & -.36 \\
\hline & & & \\
\hline
\end{tabular}




\begin{tabular}{|c|c|c|c|}
\hline DRUG & ITEMS & Factor A & Factor B \\
\hline Cocaine & 1 & .28 & .27 \\
\hline & 2 & .00 & -.38 \\
\hline & 3 & .28 & .43 \\
\hline & 4 & .50 & .57 \\
\hline & 5 & .19 & .45 \\
\hline & 6 & .36 & .00 \\
\hline & 7 & .38 & .37 \\
\hline & 8 & .00 & -.31 \\
\hline & 9 & .00 & -.36 \\
\hline & 10 & .00 & -.40 \\
\hline Prescription Painkillers & 1 & .54 & -.12 \\
\hline & 2 & .69 & .00 \\
\hline & 3 & .63 & -.13 \\
\hline & 4 & .37 & -.15 \\
\hline & 5 & .56 & -.16 \\
\hline & 6 & .59 & -.14 \\
\hline & 7 & .55 & .00 \\
\hline & 8 & -.37 & .27 \\
\hline & & & \\
\hline & & 11.56 & 7.21 \\
\hline Eariance Accountable & & 18.09 & 11.27 \\
\hline
\end{tabular}

NOTE: Factor A - Sport Performance drug item Factor B - Sport Coping drug item

TABLE 4

Cronbach's Alpha Internal Consistency Coefficients for the KDSQ $(\underline{N}=93)$

\begin{tabular}{|c|c|c|}
\hline DRUG & \# Items & Alpha \\
\hline Alcohol & 10 & .74 \\
\hline Smokeless Tobacco & 2 & N/A \\
\hline Stimulants & 9 & .59 \\
\hline Human Growth Hormone & 6 & -.13 \\
\hline Marijuana & 7 & .68 \\
\hline Steroids & 12 & .65 \\
\hline Cocaine & 10 & .28 \\
\hline Prescription Painkillers & 8 & .73 \\
\hline
\end{tabular}




\section{TABLE 5}

MANOVA Analyses of Perceptions of Illegal Drug Use in Sport $(\underline{N}=93)$

\begin{tabular}{|c|c|c|c|c|}
\hline & & Gender \& Sport & & \\
\hline EFFECT & $\mathrm{F}$ & Hypothesis $d f$ & Error $d f$ & Significance \\
\hline Gender & 1.710 & 8.0 & 76.0 & .110 \\
\hline Sport & .673 & 8.0 & 76.0 & .714 \\
\hline Gender* Sport & 1.740 & 8.0 & 76.0 & .103 \\
\hline
\end{tabular}

\begin{tabular}{|c|c|c|c|c|}
\hline & & $\begin{array}{c}\text { Sport \& } \\
\text { Socioeconomic Status } \\
\text { (SES) }\end{array}$ & \\
\hline EFFECT & $\mathrm{F}$ & Hypothesis $d f$ & Error $d f$ & Significance \\
\hline Sport & .162 & 3.0 & 83.0 & .992 \\
\hline SES & .443 & 3.0 & 83.0 & .723 \\
\hline Sport * SES & .785 & 3.0 & 83.0 & .505 \\
\hline
\end{tabular}

